\author{
Federal Reserve Bank of New York \\ Staff Reports
}

\title{
Forecasting through the Rear-view Mirror: \\ Data Revisions and Bond Return Predictability
}

\author{
Eric Ghysels \\ Casidhe Horan \\ Emanuel Moench
}

Staff Report No. 581

November 2012

Revised March 2014

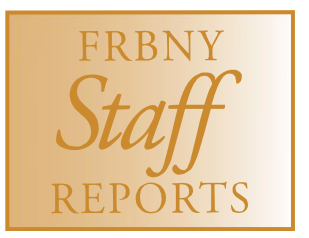

This paper presents preliminary findings and is being distributed to economists and other interested readers solely to stimulate discussion and elicit comments. The views expressed in this paper are those of the authors and are not necessarily reflective of views at the Federal Reserve Bank of New York or the Federal Reserve System. Any errors or omissions are the responsibility of the authors. 
Forecasting through the Rear-view Mirror: Data Revisions and Bond Return Predictability Eric Ghysels, Casidhe Horan, and Emanuel Moench

Federal Reserve Bank of New York Staff Reports, no. 581

November 2012; revised March 2014

JEL classification: G10, G12

\begin{abstract}
Macroeconomic data are typically subject to future revisions and released with delay. Predictive return regressions using such data therefore potentially overstate the information set available to investors in real time. We document that data revisions account for a sizeable share of in-sample and out-of-sample predictive power for Treasury returns found in macroeconomic data. This is partly explained by the fact that information contained in revisions to prior months' releases is incorporated into bond prices. Survey forecasts available in real time contain information about future revised data that is orthogonal to the real-time data and also helps to predict bond returns.
\end{abstract}

Key words: return predictability, real-time data, macroeconomic announcements, dynamic factor models

Ghysels: University of North Carolina at Chapel Hill (e-mail: eghysels@email.unc.edu). Horan: University of Michigan (e-mail: casidhe@umich.edu). Moench: Federal Reserve Bank of New York (e-mail: emanuel.moench@ny.frb.org). The authors thank their discussants Michael Halling and Lars Lochstoer, seminar participants at the Western Finance Association and the American Finance Association, and Thomas Gilbert and Jonathan Wright for useful comments and discussions. They are also most grateful to Thomas Gilbert for sharing market consensus expectations data. Weiling Liu provided excellent research assistance. The views expressed in this paper are those of the authors and do not necessarily reflect the position of the Federal Reserve Bank of New York or the Federal Reserve System. 


\section{Introduction}

The question whether excess returns on financial assets are forecastable and if so to what extent is important for a wide range of issues in economics and finance. It has been widely documented that Treasury returns can be predicted using information in lagged bond yields (see, for example, Fama and Bliss (1987), Campbell and Shiller (1991), Cochrane and Piazzesi (2005)). A number of recent papers have found additional evidence that macroeconomic factors carry predictive power for future Treasury returns over and above the information contained in current bond yields (see, for example, Ang and Piazzesi (2003), Moench (2008), Ludvigson and Ng (2009), Joslin, Priebsch, and Singleton (2010), and Wright (2011) among others). These results raise the question why the predictive information apparently contained in macroeconomic data was not fully incorporated into bond prices. One hypothesis is that bond market investors simply did not observe the information that the econometricians have used ex-post to test bond return predictability. Indeed, all of the studies cited above have used revised macroeconomic data in their empirical analyses. It is therefore conceivable that the predictive information found in macro variables was not available to bond market investors in real time.

In this paper, we revisit the evidence for bond return predictability using macroeconomic data by explicitly taking into account the real-time nature of these data. There are two key issues with the data that previous studies have used to construct macroeconomic factors for bond return prediction: (1) publication lags and (2) data revisions. In US macroeconomic data, publication lags - defined as the time it takes from the end of the calendar month a statistic measures until its first release - range from just a few days to over a month. Hence, for monthly US time series the information available in month $t$ regularly pertains to calendar month $t-1$ and often $t-2$. This is commonly not taken into account in predictive return regressions using macroeconomic series. Moreover, the first releases of macroeconomic data are typically based on projections and revised in subsequent months. In addition, most statistical agencies conduct annual revisions - mostly driven by the revision of seasonal factors - resulting in changes of the macroeconomic data years after the initial announcements. As a result, predictive regressions with revised data are de facto based on information that was not available to market participants in real time.

We start with a generic discussion of real-time versus revised data in the context of predictive regressions. This analysis is of independent interest, as it not only applies to bond return predictability. We show that using final revised data (and thus overstating the information set available to investors) can lead to biased estimates of return predictability. For example, under the null of no predictability, one will find spurious predictability when returns co-move with investors' forecasts of the final revised data. The framework we develop also allows us to formally test the hypothesis that investors have knowledge of the final data when forming their prediction. The hypothesis is resoundingly rejected. 
What happens when predictive involve real-time data? As data revisions are serially correlated, it appears reasonable to assume that market participants anticipate some of the future revisions when observing the real-time data. When this is the case, we show that the use of real-time data in predictive regressions may also lead to biased estimates. Arguably, though, such a bias may be less severe as one still obtains consistent parameter estimates under the null of no predictability. Put differently, understating the information (using only first release data) available to market participants has less severe consequences than overstating the information to market participants, as is typically done. One can interpret the use of final revised macroeconomic data in predictive bond return regressions as implicitly testing the null hypothesis that investors have knowledge of the final data when forming their forecasts. We discuss that this, in turn, implies that the predictive coefficients on the various components of the final revised data have to be the same and propose a simple test for this hypothesis.

The prior literature on bond return predictability with macro data has primarily focused on factors extracted from macroeconomic panels (see, e.g., Moench (2008), Ludvigson and Ng (2009), Ludvigson and Ng (2011), Favero, Niu, and Sala (2012)). One could argue that this practice reduces the possibility of spurious predictability from final revised data if the publication lag and data revision components were small or uncorrelated across series. However, we document that revisions represent a non-trivial share of the total variance in many macroeconomic time series ${ }^{1}$ We further show that revision components feature sizeable degrees of cross-sectional and serial correlation. The combination of publication lags and serially as well as cross-sectionally correlated revision components implies that the factors extracted from a set of revised macroeconomic data likely do not span the same space as the factors extracted from the real-time data. Consequently, the predictive information contained in macroeconomic time series should be re-assessed on the basis of factors extracted from real-time as opposed to revised data if we want to examine expected bond returns with the information available to market participants.

Explicitly taking into account the real-time nature of macroeconomic information, we find that a sizeable fraction - but not all - of the in-sample predictive power of macroeconomic variables for future Treasury bond returns is explained by the data revision and publication lag components. We further decompose the revised macroeconomic data into predictable and unpredictable components in future revisions using various specifications of the real-time information set potentially available to investors. We find no evidence that real-time macro data, past revisions or financial market indicators carry information about future revised data that helps to explain their predictive power for bond returns. However, the predictable part of future revisions explains some of the return predictability found in revised macro data

\footnotetext{
${ }^{1}$ Several studies document similar or related findings about revisions in US macroeconomics data, see e.g. Runkle (1998), Croushore and Stark (2001), Croushore and Evans (2006), Aruoba (2008), Jacobs and Van Norden (2011), among others.
} 
when we augment the information set potentially available to investors with real-time survey data on future macroeconomic conditions. Yet, even when taking into account the survey information we find that the unpredictable component of final revised data carries significant predictive power for future bond returns. Hence, a sizeable fraction of the bond return predictability documented for revised macro data appears to be spurious. We confirm these results in a truly real-time out-of-sample forecast exercise. Indeed, the strong out-of-sample predictive power of revised data is significantly diminished when only information available to investors in real time is used to forecast future bond returns. Still, we find moderate but statistically significant degrees of predictability of bond returns in data available in real time.

While the previous results are based on factors extracted from a panel of macroeconomic time series, we also consider bond return prediction using nonfarm payroll employment, which is arguably the macroeconomic time series most closely watched by investors. $2^{2}$ We find similar results as with the factor analysis: a significant share of the predictive information in final data is carried by the revision component, and the hypothesis that investors have knowledge of the final data when forming their prediction is rejected. We further study the response of the Treasury yield curve to announcements of changes in total monthly non-farm payroll. Our findings suggest that expectations of future revisions do not affect the yield curve reaction to labor market news in economic expansions but have a small impact in recessions. This is in contrast to Gilbert (2011) who finds a strong reaction of the S\&P 500 index to future revisions on days of payroll announcements with opposite signs in recessions and expansions. Gilbert (2011) also finds little impact of the equity market to previous months' revisions. While we confirm this result for Treasury yields in economic expansions, we find a strong reaction to prior revisions in recessions. In fact, during economic downturns, surprises to the new month's release have a muted impact on the yield curve, but the revisions to prior months' announcements have a sizeable and significant effect. These results indicate that the information contained in the first few revisions after the initial announcement are incorporated into bond prices, thereby partly explaining the predictive power of revisions for future bond returns.

Our research follows in the footsteps of some recent papers documenting the potential impact of mis-specification of information sets on the estimation of asset pricing models. For example, Christoffersen, Ghysels, and Swanson (2002) re-examine macroeconomic mimicking portfolios, designed to maximize correlation with macroeconomic news. They find that when final data are used, as in Chen, Roll, and Ross (1986), as opposed to real-time series, one obtains very different tracking portfolios and loadings when projected on equity

\footnotetext{
${ }^{2}$ This indicator has been widely documented to drive price reaction in fixed-income markets (for example Jones, Lamont, and Lumsdaine (1998) and Fleming and Remolona (1999)), equity markets (for example Boyd, Hu, and Jagannathan (2005) and Gilbert (2011)), and foreign exchange markets (for example Andersen, Bollerslev, Diebold, and Vega (2003) and Ehrmann and Fratzscher (2005)).
} 
returns. In a similar vein, Guo (2003) argues that the out-of-sample predictive power of the consumption wealth ratio proposed by Lettau and Ludvigson (2001) is negligible in real time. Beber, Brandt, and Luisi (2013) construct a real-time measure of economic activity from macroeconomic news releases and find evidence that it predicts future stock returns. A few papers have also studied the usefulness of real-time macroeconomic data for predicting foreign exchange returns. Ehrmann and Fratzscher (2005) document that a sizeable fraction of the dynamics of the US dollar/German mark exchange rate can be explained by real-time macroeconomic news surprises for these two economies. Moreover, Molodtsova, NikolskoRzhevskyy, and Papell (2008) document return predictability for the US dollar/German mark nominal exchange rate using real-time but not revised data. While this line of research has so far mainly focused on equity and foreign exchange markets, fixed income markets for which macroeconomic news arguably may matter more have not been studied $:^{3}$

Our paper also relates to a broader literature on the usefulness of real-time data in macroeconomic research. For example, Orphanides (2001) stresses the importance of examining monetary policy decisions with vintage data rather than final revised series. Moreover, our real-time data is based on outstanding research efforts undertaken at the Federal Reserve Banks of St. Louis and Philadelphia, making such data publicly available and easy to use (see Croushore and Stark (2001)). Appraising forecasting performance, particularly of macroeconomic series, with final versus real-time data has also been discussed extensively in the literature, see e.g. Stark and Croushore (2002), Orphanides and van Norden (2002), Koenig, Dolmas, and Piger (2003), Croushore and Evans (2006), Croushore (2006), among many others.

The paper is organized as follows. In Section 2, we introduce our notation and provide a discussion of the econometric issues involved in running predictive regressions with revised versus real-time data. In Section 3, we give a detailed overview of the real-time data set that we construct to analyze the question at hand and discuss the time series properties of the revision components. We document our empirical findings in Section 4 . Section 5 concludes.

\section{Predictive Regressions and Data Revisions}

In this section, we first introduce our notation for the vintages of macroeconomic data and the various revision components. We then provide a formal econometric analysis of realtime data issues in predictive regressions, which, to the best of our knowledge, has not been discussed in the extant literature.

\footnotetext{
${ }^{3}$ An exception is Barillas (2013) who estimates an affine term structure model with daily data explicitly taking into account the real-time macroeconomic information set of investors. He finds evidence that macroeconomic data help explain Treasury risk premia over and above the information contained in contemporaneous yields.
} 


\subsection{Decomposing Final Revised Macroeconomic Data}

We denote the period $T$ vintage of an observation for variable $i$ in month $t$ by $x_{i t \mid T}$. In our analysis, $T$ is the end of the sample. Throughout the paper we will refer to the period $T$ vintage simply as the final revised observation, thus ignoring that future revisions will result in further changes of past observations. We denote $x_{i t}$ the last reading on variable $i$ that was available to investors in period $t$. In practice, since almost all macroeconomic time series are released with a one or two-month lag, the release of new information in month $t$ typically pertains to period $t-1$ or $t-2$, i.e. $x_{i t}=x_{i t-1 \mid t}$ or $x_{i t}=x_{i t-2 \mid t}$. For simplicity, we will uniformly refer to the real-time observation available in $t$ as $x_{i t}=x_{i t-1 \mid t}$.

We can then decompose the final revised observation into two components:

$$
x_{i t \mid T}=x_{i t-1 \mid t}+\nu_{i t \mid T},
$$

where

$$
\nu_{i t \mid T}=\left(x_{i t \mid T}-x_{i t \mid t+1}\right)+\left(x_{i t \mid t+1}-x_{i t-1 \mid t}\right)
$$

contains two elements: a component that is purely related to future revisions of the initial announcement, $x_{i t \mid T}-x_{i t \mid t+1}$, and one that captures the fact that macroeconomic data are released with a lag, $x_{i t \mid t+1}-x_{i t-1 \mid t}$.

For most of the paper, we will consider the two components separately so as to shed some light on which is more informative about future excess bond returns. As previously discussed, revisions in macroeconomic data do not only occur in the few months after the initial release, but also at regular intervals in future years as so-called annual or benchmark revisions. These revisions mainly comprise updated estimates of seasonal factors, but also changes in the sampling and aggregation methodologies and other types of information. While benchmark revisions to employment and industrial production data are conducted once a year, benchmark revisions to other series may occur less frequently 4 It will be instructive to further decompose the cumulative revisions to a macroeconomic time series from its initial release until the final observation into benchmark revisions and initial data revisions. Since benchmark revisions are often announced at the same time as revisions to prior months' observations, it is not possible in certain months to separate the two types of revisions. We therefore decompose the total cumulative revision into

$$
x_{i t \mid T}-x_{i t \mid t+1}=\left(x_{i t \mid T}-x_{i t \mid t+13}\right)+\left(x_{i t \mid t+13}-x_{i t \mid t+1}\right),
$$

\footnotetext{
${ }^{4}$ Various authors, including Gilbert (2011), refer to "annual benchmark revisions". The latter are mostly driven by revisions of seasonal factors. Since seasonal adjustment filters are two-sided filters, as discussed for instance in Ghysels and Osborn (2001), statistical agencies update seasonal factors yearly as future data becomes available. The notion of benchmark revision goes beyond these annual revisions, however, as comprehensive revisions of the NIPAs mark the culmination of an estimating cycle that typically takes five years. A comprehensive revision, or benchmark revision according to the BEA, is timed to incorporate the benchmark input-output (I-O) accounts, which provide levels of the components of GDP for the benchmark year. For further details see http://www.bea.gov/faq/index.cfm?faq_id=126. In this paper, for simplicity, we label all revisions more than one year after the initial release as benchmark revisions.
} 
where $x_{i t \mid t+13}-x_{i t \mid t+1}$ comprises all revisions occurring over the twelve months after the initial announcement and $x_{i t \mid T}-x_{i t \mid t+13}$ aggregates all revisions occurring at later dates. In most cases, the former component contains the initial major seasonal factor revision. The revisions to seasonal factors are important, since any such revision implies that the seasonally adjusted series are revised upward or downward - and such revisions within the first year can be substantial.

\subsection{Predictive Regressions: Real-time versus Final Data}

We revisit the question whether macroeconomic variables carry information useful for predicting excess bond returns that is not subsumed by the cross-section of contemporaneous bond yields. Let $Z_{t}$ denote a $K \times 1$ vector of conditioning variables obtained from the crosssection of bond yields in period $t$. These could be individual forward rates as in Fama and Bliss (1987), a linear combination of five forward rates as in Cochrane and Piazzesi (2005), or principal components of yields as in Joslin, Singleton, and Zhu (2011) and Adrian, Crump, and Moench (2013). It is standard practice in the literature to establish the predictive power of these conditioning variables by estimating the regression involving $r x_{t+12}^{(n)}$, the one-year excess holding period return on a $n$-year bond:

$$
r x_{t+12}^{(n)}=c_{n}+\beta_{n}^{\prime} Z_{t}+\epsilon_{t+12}^{(n)}, \quad t=1, \ldots, T-12,
$$

via OLS and then assessing the statistical and economic significance of the estimated coefficients $\hat{\beta}_{n}$ for holding period excess returns on bonds of different maturities. In principle, one can easily assess whether macroeconomic information is useful for predicting excess bond returns beyond the information contained in the yield curve factors $Z_{t}$ by augmenting regression (4) with a set of $N \times 1$ macroeconomic predictor variables $x_{t}$ :

$$
r x_{t+12}^{(n)}=c_{n}+\gamma_{n}^{\prime} x_{t}+\beta_{n}^{\prime} Z_{t}+\epsilon_{t+12}^{(n)}, \quad t=1, \ldots, T-12 .
$$

To streamline the notation and simplify the derivations, we will momentarily drop the maturity $n$ and assume that we know the population coefficients $c$ and $\beta$ in the above regression. Moreover, defining $\widetilde{r x}_{t+12} \equiv r x_{t+12}-c-\beta^{\prime} Z_{t}$, and assuming $x_{t}$ is a single regressor, we obtain a simplified version of equation (5) as follows:

$$
\widetilde{r x}_{t+12}=\gamma x_{t}+\epsilon_{t+12}, \quad t=1, \ldots, T-12 .
$$

which is a classical predictive regression. The discussion about preliminary macro data releases and revisions prompts us to think about the proper specification of the predictive regression. To do so, let us define:

$$
x_{t \mid T}=E_{t}\left[x_{t \mid T}\right]+e_{t \mid T}
$$

where $E_{t}\left[x_{t \mid T}\right]$ is the market expectation at time $t$ of $x_{t \mid T}$, the final release. By construction, $e_{t \mid T}$ is orthogonal to all information available to market participants at time $t$. It is important 
to note that the decomposition in equation (1) is not the same as in (7), unless $E_{t}\left[x_{t \mid T}\right]=$ $x_{t-1 \mid t}$. Most likely, the latter does not hold for a variety of reasons. First of all, there is the publication lag issue. Second, it is unlikely that statistical agencies have the same information set as market participants (see Sargent (1989) for a discussion of models of statistical agency data releases and rational expectations). Third, market participants may anticipate some of the future revisions, namely using equation (1) and (2) we have:

$$
\begin{aligned}
x_{t \mid T} & =E_{t}\left[x_{t \mid T}\right]+e_{t \mid T} \\
& =x_{t-1 \mid t}+E_{t}\left[\nu_{i t \mid T}\right]+e_{t \mid T} \\
& =x_{t-1 \mid t}+E_{t}\left[\left(x_{i t \mid t+1}-x_{i t-1 \mid t}\right)\right]+E_{t}\left[\left(x_{i t \mid T}-x_{i t \mid t+1}\right)\right]+e_{t \mid T}
\end{aligned}
$$

Most likely, $E_{t}\left[\left(x_{i t \mid t+1}-x_{i t-1 \mid t}\right)\right]$ and $E_{t}\left[\left(x_{i t \mid T}-x_{i t \mid t+1}\right)\right]$ are non-zero, particularly if revisions (the second term) are partly predictable.

To proceed we make some key assumptions. Namely, first of all:

$$
\widetilde{r x}_{t+12}=\gamma_{0} E_{t}\left[x_{t \mid T}\right]+\epsilon_{t+12}, \quad t=1, \ldots, T-12 .
$$

which means that the predictive regression is formulated in terms of market expectations, not final releases since the latter violate the information timing of market participants. A second assumption we make is that $x_{t \mid T}$ is the true data, i.e. there is no remaining error. By assuming that the final release is the true process we avoid complications associated with latent variables due to the final remaining error 5 Finally, a third assumption is that market participants care about the final release. This is a logical consequence of the second assumption and also an assumption entertained in the related literature on announcement effects, see in particular Gilbert (2011), which we will study in Section 4.6.2.

Note that we do not assume that $\gamma_{0}$ is zero, although the null hypothesis that it is zero will of course be of special interest. Against the background of equation (9), we consider two empirical regressions:

$$
\widetilde{r x}_{t+12}=\gamma_{F} x_{t \mid T}+\epsilon_{t+12}^{F}, \quad t=1, \ldots, T-12 .
$$

where the econometrician uses final data to run predictive regressions, and:

$$
\widetilde{r x}_{t+12}=\gamma_{P} x_{t-1 \mid t}+\epsilon_{t+12}^{P}, \quad t=1, \ldots, T-12 .
$$

where instead first released data are used. We are interested in the relationship between $\gamma_{0}$ and respectively, $\gamma_{F}$ and $\gamma_{P}$. Some algebraic computations yield that asymptotically the OLS estimates converge to:

$$
\begin{aligned}
p \lim \hat{\gamma}_{F} & =\gamma_{0} \frac{\operatorname{Var}\left(E_{t}\left[x_{t \mid T}\right]\right)}{\operatorname{Var}\left(E_{t}\left[x_{t \mid T}\right]\right)+\operatorname{Var}\left(e_{t \mid T}\right)}+\frac{\operatorname{Cov}\left(\epsilon_{t+12}, e_{t \mid T}\right)}{\operatorname{Var}\left(E_{t}\left[x_{t \mid T}\right]\right)+\operatorname{Var}\left(e_{t \mid T}\right)} \\
\operatorname{plim} \hat{\gamma}_{P} & =\gamma_{0} \operatorname{Corr}\left(E_{t}\left[x_{t \mid T}\right], x_{t-1 \mid t}\right) \frac{\sqrt{\left.\operatorname{Var}\left(x_{t-1 \mid t}\right]\right)}}{\sqrt{\operatorname{Var}\left(E_{t}\left[x_{t \mid T}\right]\right)}}
\end{aligned}
$$

\footnotetext{
${ }^{5}$ Various authors have discussed measurement error models, including Berkson (1950), Durbin (1954), Mankiw, Runkle, and Shapiro (1984), Sargent (1989), among others.
} 
A few observations emerge from these calculations. First, using final revised data which overstate the information available to market participants, results in biased estimates. In particular, under the null that $\gamma_{0}=0$, we note that the bias depends on the covariance between market expectation errors and the regression prediction error (which under the null equals $\widetilde{r x}_{t+12}$ ). If the latter is positive, then there is an upward bias. Therefore, using final revised data, in lieu of market expectations, yields spurious predictability results.

In contrast, the use of preliminary release data has interesting consequences under the null that $\gamma_{0}=0$. Indeed, the predictive regression still yields consistent estimators, although the information of market participants is understated. Unfortunately, this is not the case when $\gamma_{0}$ is non-zero. Then, the predictive regression will most likely underestimate the true predictability since the correlation term is less than one (but positive), and the ratio of standard errors will be less than one too. Hence, using preliminary releases will yield downward biases in predictive regressions. If we end up with a good proxy for $E_{t}\left[x_{t \mid T}\right]$, assuming that $x_{t-1 \mid t}$ is not, we will eliminate the bias, since the correlation will increase to one, and so will the ratio of standard errors. Finding good proxies for $E_{t}\left[x_{t \mid T}\right]$ means that we have to think about market expectations of future revised data beyond those incorporated in the preliminary release, a task to which we turn later in the paper.

Based on the above arguments, we can also introduce a simple specification test for the use of final data in predictive regressions. Intuitively, if investors had knowledge of the final revised data when making their predictions, then the preliminary release and the revision components should have equal predictive coefficients. The test is thus based on an expansion of equation (10) using the decomposition of $x_{t \mid T}$ in equation (1), namely:

$$
\begin{aligned}
\widetilde{r x}_{t+12} & =\gamma_{F}\left[x_{t-1 \mid t}+\nu_{t \mid T}\right]+\epsilon_{t+12} \\
& =\gamma_{F} x_{t-1 \mid t}+\gamma_{F} \nu_{t \mid T}+\epsilon_{t+12}
\end{aligned}
$$

where the second equation yields a testable restriction, namely:

$$
\widetilde{r x}_{t+12}=\gamma_{F}^{1} x_{t-1 \mid t}+\gamma_{F}^{2} \nu_{t \mid T}+\epsilon_{t+12}
$$

with the null hypothesis $\gamma_{F}^{1}=\gamma_{F}^{2}$. Note the simplicity of the test, which consists of running a predictive regression onto the first release and revision components jointly. Note also that we can run this test for a single maturity $n$, or as a joint test for a system of maturities with the null being tested across the selected $n$.

We can further decompose $\nu_{i t \mid T}$ according to equation (2) yielding the regression:

$$
\begin{aligned}
\widetilde{r x}_{t+12}= & \gamma_{F}^{1} x_{t-1 \mid t}+\gamma_{F}^{2}\left(x_{i t \mid t+1}-x_{i t-1 \mid t}\right) \\
& +\gamma_{F}^{3}\left(x_{i t \mid T}-x_{i t \mid t+1}\right)+\epsilon_{t+12}
\end{aligned}
$$

with a similar null hypothesis about equality of the slopes across the regressors. When we reject the null in either equation (14) or (15), we can of course also entertain hypotheses as to which individual coefficient is statistically significant. 


\section{Data}

We construct one-year excess holding period returns for 2-, 3-, 4-, and 5-year U.S. Treasury notes provided in the Fama-Bliss data set of the Center for Research in Securities Prices (CRSP). These data have been used e.g. by Cochrane and Piazzesi (2005) who document that a single linear combination (the CP factor) of forward rates captures much of the predictable variation of one-year excess returns on bonds of different maturities. Since the loadings of the CP factor have a tent-shaped form with a peak at the three-to-four year forward, one can well approximate the predictive information for future bond returns contained in current market prices by using two yield spreads: the one between the three-year and the one-year yield (labeled "S31") and the one between the five-year and the four-year yield (labeled "S54"). Using observable spreads instead of an estimated linear combination as a regressor has the advantage of avoiding potential errors-in-variables and look-ahead biases.

To study the additional predictive content of macroeconomic factors, we construct a panel of time series that are published at a monthly frequency and for which the initial release numbers as well as the release dates are available for a sufficiently long time span. Unfortunately the availability of real-time data is sparse before the 1980s. We find that a data set covering 68 economic time series and starting in March 1982 maximizes the total number of time series and cross-sectional observations. These series include measures of industrial production, employment, housing indicators, personal income, price indices and the money stock. We obtain these data from the Archival Federal Reserve Economic Database (ALFRED) at the Federal Reserve Bank of St. Louis. Appendix A provides a detailed account of our real-time data set, along with the original data source, the first date of real-time data availability, as well as the transformations that we apply to the series in order to ensure stationarity. Our data set broadly covers the same economic categories as the one used by Ludvigson and Ng (2009) (LN1 henceforth) and Ludvigson and Ng (2011) (LN2 henceforth). However, Ludvigson and $\mathrm{Ng}$ also include in their panel a number of financial time series and extract factors from the joint data set. We are interested in the predictive content of macroeconomic data in real-time above and beyond the information already contained in market prices. We therefore restrict ourselves to a data set covering only macroeconomic time series that are potentially subject to publication lags and data revisions.

Our results using factor analysis are based on the sample from March 1982 until December 2007. We end our sample in 2007 for multiple reasons. First, we want to ensure that our final revised data are free from any revisions occurring in the months after the initial announcements. Second, we exclude the financial crisis and the ensuing period of largescale asset purchases by the Federal Reserve which potentially have resulted in a break of the relationship between macroeconomic factors and Treasury returns. Finally, ending the sample in 2007 allows us to directly compare our results to those of LN1 and LN2. In 
unreported results which are available upon request we have found that our findings are robust to extending the sample to 2011.

In Sections 4.4 and 4.5 we use survey forecasts of economic conditions as additional measures of the macroeconomic information set available to investors in real time. Specifically, we use monthly consensus forecasts for horizons from the current quarter to four quarters ahead from the Blue Chip Economic Indicators survey (BC survey in short). These forecasts are available for the following variables: real GNP/GDP, industrial production, the unemployment rate, the GNP/GDP deflator, CPI inflation, and the three-month Treasury bill yield.

In Section 4.6 we study the predictive power of nonfarm payroll employment for future bond returns. We further analyze the effects of nonfarm payroll news announcements on the Treasury yield curve. In this exercise, we use the daily yields on constant maturity Treasuries from the Federal Reserve's H.15 release for the 1-year, 3-year, 5-year, 10-year and 20-year maturities. We further use the median market expectation for nonfarm payroll news announcements from the Money Market Services (MMS) database (as in Gilbert (2011)) before 1999, and from Bloomberg starting in 2000.

\subsection{Publication Lags and Data Revisions}

Investors who aim to use macroeconomic information to predict bond returns in real time face two issues. First, most macroeconomic time series are released with a lag, and second, they are typically subject to subsequent revisions. Both issues are important when assessing the usefulness of macro data for predicting bond returns ex-post. In this section, we set the stage for our analysis by documenting that publication lags are widespread and that data revisions capture a sizeable share of the total variation of macroeconomic time series. We define revisions as the difference between the last available vintage and the initial announcement of a given time series in a given calendar month.

The first row in Table 1 provides summary statistics across the 68 time series in our panel for the number of days between the last day of the calendar month and the publication date of the first release for a given variable. The table shows that the mean and the median series in our data set are on average published about 13 days after the end of the calendar month that they measure. While some series are published with an average lag of only about five days, for others it takes more than one month, on average, before they are released. This underscores that the information set available to investors in real time may differ quite substantially from the one available to the econometrician in an ex-post analysis of bond return predictability.

We now turn to the importance of data revisions. The second row in Table 1 provides the same summary statistics for the ratio of sample variances of the revision component and the final revised series across variables. Here, we do not take into account the publication 
lag, but simply compare the revision as the difference between the first release and the final revised vintage of a variable for a given month. The average of the variance ratios across the series in our panel amounts to 0.68 , indicating that revision components make up for a sizeable fraction of the total variation in final revised macroeconomic time series. Hence, the information content of the final and first vintages of macroeconomic time series is potentially quite different.

Our results are in line with earlier findings reported in Aruoba (2008) who documents the empirical properties of revisions to major macroeconomic variables and also finds that they are large relative to the variation in the original variables and feature substantial degrees of serial correlation. Regarding the latter, we find similar results. Looking at the summary statistics of the AR(1) coefficients for the revision components across the 68 variables shown in the third row of Table 1, we see that the average coefficient equals -0.44 suggesting that there is a substantial amount of serial correlation in these revision errors. In particular, most revision components are negatively correlated indicating that a positive revision in one month is often followed by a negative revision in the next month. To the extent that these revisions are systematic and make up for a substantial share of the variance in the final revised data, it is therefore not unlikely that their serial correlation contributes to the predictive power for bond returns found in that data.

Revision errors are also cross-sectionally correlated, as shown by the fourth row in Table 1. This row documents the cross-sectional distribution of sample $R^{2}$ s obtained from regressing the 68 individual data revision components onto their first principal component. The cross-sectional mean amounts to $9 \%$ with a maximum of $67.3 \%$, indicating that there is a considerable degree of co-movement of revisions across macroeconomic variables. In line with this number, we find that the first principal component extracted from the revision components explains $9 \%$ of their total variation while the first three principal components explain $23 \%$. Hence, data revision components are not only serially but also cross-sectionally correlated. This implies that the factors extracted from real-time data do not necessarily span the same space as the factors extracted from revised data. The finding that revisions

are cross-sectionally correlated is consistent with Swanson, Ghysels, and Callan (1999) who document non-trivial multivariate dependence patterns in data revisions.

Overall, these summary statistics imply that bond return predictions based on macroeconomic factors might be quite different depending on whether real-time or revised data are used. In the sections that follow, we quantify this difference.

\section{Empirical Results}

This section summarizes the empirical results of the paper. In Section 4.1 we compare the factor spaces spanned by the principal components extracted from a panel of revised macro as well as financial time series used in LN2. We find that the first factor extracted from our 
revised data set is highly correlated with the first factor in the LN2 data set which is the main driving force of the bond return predictability in their analysis. We then show in Section 4.2 that while the first principal component of our final revised data set predicts future bond returns as well as the first factor in LN2, the first principal component extracted from the real-time version of the same data set carries much less predictive power. We continue by decomposing the revised factor's in-sample predictive power into the real-time, publication lag, and revision components in Section 4.3. We document that the real-time component does not significantly predict future bond returns but that instead most of the predictability comes from the revision components. Next, we assess in Section 4.4 whether the components of final revised data that are predictable in real-time or their unpredictable components drive the forecasting power of final revised data. We then document that the in-sample results carry over to a pure out-of-sample setting in Section 4.5. Finally, in Section 4.6 we analyze predictive regressions using nonfarm payroll employment as forecasting variable and also study the effects of revisions on announcement day returns following the analysis of Gilbert (2011).

\subsection{A Comparison of Factor Spaces}

LN2 extract eight factors from their panel of 131 macroeconomic and financial time series and find that a subset of them best predicts excess bond returns in-sample. This subset comprises the first and eighth principal component (henceforth PC) as well as the second power of the fifth $\mathrm{PC}$ and the third power of the first PC. We denote the latter by $f_{1 t}^{L N}, f_{8 t}^{L N},\left(f_{5 t}^{L N}\right)^{2}$,

and $\left(f_{1 t}^{L N}\right)^{3}$, respectively. Similarly, we label the principal components extracted from our revised and real-time data set as $f_{1 t \mid T}, \ldots, f_{8 t \mid T}$ and $f_{1 t-1 \mid t}, \ldots, f_{8 t-1 \mid t}$, respectively. Their results further suggest that the first principal component, which heavily loads on business cycle indicators such as measures of production and employment, captures the bulk of the predictive power of the macro factors for bond returns. Since our data set captures fewer series than the one employed by LN2, it is not clear ex-ante whether the factors extracted from our panel of revised data similarly capture predictive information for bond returns.

Table 2 reports the pairwise correlation coefficients between the first eight PCs extracted from our data set with the four factors which LN2 find to best predict bond returns in their sample. The upper panel of the table shows these correlations for the PCs extracted from our revised data, and the lower panel reports them for the PCs extracted from the real-time data. As the upper panel shows, the first PC from LN2's data set and the first principal component from our revised data are strongly correlated with a pairwise correlation coefficient of 0.85 . Table 2 also shows that none of the remaining factors extracted from our revised data set are much correlated with the set of PCs that LN2 find to have forecasting power for bond returns in their sample.

The second panel in Table 2 reports the pairwise correlation coefficients between the LN2 
factors and the first eight PCs extracted from our real-time data set. Most of the pairwise correlations are considerably lower for the real-time counterparts, consistent with our earlier finding that publication lags and data revisions represent a sizeable fraction of the variance in the revised data. Most importantly, the pairwise correlation coefficient between $f_{1 t}^{L N}$ and the first principal component in our data set drops from 0.85 to 0.55 when using real-time data. This suggests that the predictive power for bond returns contained in the macro data might well be different when using real-time data. All pairwise correlations of higher order PCs with the LN2 factors are essentially zero. In our subsequent analysis we therefore focus on analyzing the predictive content of the first PC extracted from both the revised and the real-time version of our panel of 68 monthly time series.

Figure 1 superimposes the first principal components extracted from our revised and realtime data. While both factors are clearly correlated, they differ markedly in some periods. Most importantly, the real-time factor $f_{1 t-1 \mid t}$ visibly lags the revised factor $f_{1 t \mid T}$ highlighting the importance of the lags with which macroeconomic data are published.

\subsection{In-Sample Predictive Regressions}

We now compare the in-sample predictive power of the final revised factor $f_{1 t \mid T}$ and the realtime factor $f_{1 t-1 \mid t}$ with respect to the set of principal components that LN2 find to be the best forecasters of excess bond returns. We then turn to the question whether the revision components comprised in final revised data carry predictive information that is not captured by the real-time components of the data or contemporaneous bond yields.

Table 3 provides estimation results for a version of equation (4) which compare the predictive power of the different sets of principal components for one-year excess holding period returns on Treasury notes with two and five years to maturity. The equation is specified as follows:

$$
r x_{t+12}^{(n)}=\alpha_{n}+\beta_{1 n}^{\prime} S 31_{t}+\beta_{2 n}^{\prime} S 54_{t}+\gamma_{n}^{\prime} F_{t}^{I}+\epsilon_{t+12}^{(n)}
$$

where $S 31_{t}$ is the spread between the three-year and the one-year yield, and $S 54_{t}$ the spread between the five-year and the four-year yield. The factors $F_{t}^{I}$ are either real-time or final. The first three columns report the coefficients and corresponding $t$-statistics for the regression constant and the two yield spreads S31 and S54. The next four columns show the coefficients for the factors that LN2 found to be the best predictors of bond returns in their data set. We use the factors estimated by LN2 for the full sample from January 1964 through December 2007, but use March 1982 as the start date for the regression to enable direct comparison with the factors extracted from our shorter data set. The right-hand side columns replace $f_{1 t}^{L N}$ and its cubed version $\left(f_{1 t}^{L N}\right)^{3}$ by the corresponding counterparts of $f_{1 t \mid T}$ and $f_{1 t-1 \mid t}$, respectively. This allows us to directly assess the individual significance as well as goodness of fit as measured by the adjusted $R^{2}$ (reported in the last column) of the predictive bond regressions 
obtained using the three different information sets. All standard errors are Newey-West adjusted with a maximum lag length of 18 months.

We first estimate a predictive return regression using only the two yield spreads as regressors (first row in both panels). For both maturities, the coefficients on the two spreads are strongly statistically significant with opposite signs, in line with the tent-shaped factor loadings documented by Cochrane and Piazzesi (2005). The adjusted $R^{2}$ 's of the regressions are $18 \%$ and $19 \%$, respectively. This regression provides the benchmark for the amount of return predictability contained in contemporaneous bond yields. The second row adds the first principal component of the panel of final revised macroeconomic data from LN2, $f_{1 t}^{L N}$. The coefficient is negative and strongly statistically significant and the adjusted $R^{2}$ jumps to $28 \%$ (23\%) for the two-year (five-year) maturity. This is in line with LN2's findings that macroeconomic data contain information useful for predicting bond returns that is not captured by contemporaneous bond yields.

The third row adds as regressors the third power of $f_{1 t}^{L N}$, the squared observations of the fifth principal component as well as the eighth principal component from the Ludvigson- $\mathrm{Ng}$ data set. These regressors have been found by LN2 to be the most useful in addition to $f_{1 t}^{L N}$ in predicting one-year excess bond returns in-sample as well as out-of-sample. Interestingly, the predictive power contained in these regressors is somewhat weaker in our sample starting in March 1982 and the adjusted $R^{2}$ 's only increase slightly. Hence, the first principal component explains the bulk of the predictive power of the macro factors. This is in line with the evidence in LN1 as well as LN2; both find that the first principal component is the single best predictor of excess returns in their respective samples. Since the first factor mainly loads on variables capturing production and labor market dynamics, LN interpret this finding as being consistent with models of countercyclical risk premia.

We now compare the predictive power of the LN factors with those extracted from the final revised and the real-time versions of our panel of 68 macroeconomic time series. The fourth row in both panels uses only the first principal component extracted from the final revised series $f_{1 t \mid T}$, controlling for the two yield spreads. For both maturities, the coefficients are highly statistically significant, albeit somewhat smaller in absolute value than those obtained with $f_{1 t}^{L N}$. Moreover, the adjusted $R^{2}$ is a bit lower than the one implied by $f_{1 t}^{L N}$ alone for the two-year maturity but a bit higher for the five-year maturity. Thus, the first principal component from our final revised panel predicts bond returns about as well as the first principal component from LN2. This is also true when we control for the other factors used in the optimal predictor set of LN2 (row five).

In row six, we replace the revised factor by the first principal component of the realtime observations of the 68 series, $f_{1 t-1 \mid t}$. The coefficients on this factor are about half in absolute values of those implied by the final revised factor, only statistically significant at the $10 \%$ level for the two-year maturity and statistically insignificant at conventional levels for the five-year maturity. Moreover, the $R^{2}$ drops from $26 \%$ (24\%) to $21 \%(21 \%)$, 
respectively, for the two-year and the five-year maturity. Hence, the real-time observations of our macroeconomic data panel contain considerably less predictive information for future bond returns than the final revised observations. Adding the remaining optimal predictors from LN2 to the regression does not alter that conclusion (row seven).

In summary, the results in this section show that the in-sample predictive power of macroeconomic factors for bond returns is substantially reduced when real-time as opposed to final revised data are used.

\subsection{Decomposing the Predictive Power of Final Revised Data}

In the previous section we have documented that a final revised macro factor has considerably stronger predictive power for future bond returns than its real-time counterpart. We now assess which components of final revised data mainly contribute to the superior predictive ability.

Table 4 shows results for in-sample regressions of one-year excess holding period returns on two-year and five-year Treasury notes on one-year lagged explanatory variables. As before the first column reports as a benchmark a specification using only the two yield spreads as predictor variables. Both are highly statistically significant with opposite signs and together explain 18\% (19\%) of the variation in returns on two-year (five-year) bonds.

The second column adds the first principal component from our panel of 68 final revised macro time series. This is the same specification as in row four of the previous table but is restated for reference here. For both maturities, the coefficients are highly statistically significant and the adjusted $R^{2}$ in both regressions increases considerably. This suggests that the final revised data carry predictive information about future excess bond returns beyond what is captured by contemporaneous yields.

The following columns repeat these regressions by combining the two spreads with the various components of the final revised macro factor $f_{1 t \mid T}$. The third column uses as predictor the component consisting of the first releases of all macro series in our panel, $\hat{\Lambda}^{\prime} X_{t \mid t+1}$. Specifically, we apply the loadings of the first principal component extracted from the final revised data to the first release observations of all 68 series in our panel. For both maturities, the coefficients drop by about $50 \%$ and become statistically insignificant. Moreover, the adjusted $R^{2}$ 's also decrease markedly, indicating that the first releases contain considerably less predictive information than the final revised series. Column (4) shows the same regression using the component of $f_{1 t \mid T}$ that was available in real time, $\hat{\Lambda}^{\prime} X_{t-1 \mid t}$. The results are essentially the same as for the first release: both coefficients are insignificant and the adjusted $R^{2}$ 's are barely different from the benchmark regressions using only yield curve information. Thus, we do not find evidence of significant predictability contained in the real-time components of the final revised series. In order to specifically assess whether the publication lag component captures predictive power for future bond returns, we use as re- 
gressor the difference between the first release and real-time components of the final revised factor in row (5). For both maturities, the coefficient on the publication lag component is economically and statistically zero.

The previous results indicate that at least some of the predictive information in final revised series must be due to the data revision components comprised in these. Columns (6) through (9) assess which of these components are most strongly correlated with future bond returns. Column (6) uses the component capturing the full sample revisions contained in the final revised factor, $\hat{\Lambda}^{\prime}\left(X_{t \mid T}-X_{t \mid t+1}\right)$. We see that these have strikingly strong predictive power for future bond returns. In fact, the coefficients are of the same order of magnitude or larger in absolute value than those for the final revised data and are strongly statistically significant for both maturities.

Columns (7) and (8) decompose the cumulative future revisions further into two components: the revisions occurring over the first year after the initial release, $\left(X_{t \mid t+13}-X_{t \mid t+1}\right)$, and all revisions made in future years, $\left(X_{t \mid T}-X_{t \mid t+13}\right)$. It is important to note that the latter, even if they are incorporated into bond prices at later dates, by construction cannot affect the one-year holding period returns that we aim to predict. Despite this fact, both components of the revisions turn out to be about equally important with similar adjusted $R^{2}$ 's and statistically significant coefficients. Hence, a significant portion of the predictive information contained in final revised data is driven by data revisions, both near-term and future benchmark revisions.

The last column then lumps together the three main components of the final revised factor: the real-time information, the publication lag, and all future revisions. In this joint regression, the adjusted $R^{2}$ 's increase markedly and exceed those reported for the regression using the final revised factor (column 2). Moreover, all three components become individually statistically significant. Even though the coefficient on the real-time component is the least significant for both maturities, this regression suggests that when considered jointly the different components of final revised data all carry some information about future bond returns. As we discussed in Section 2.2, the hypothesis that market participants use information about the final values of the macroeconomic predictor variables when forecasting bond returns implies that the coefficients on all three components have to be equal. In our linear regression framework, this hypothesis can easily be tested using an $F$-test. The bottom two rows of each panel provide the test statistic and corresponding $p$-value for the null hypothesis that the coefficients on the real-time, publication lag, and revision components are the same. For both maturities, the null is rejected with very high confidence levels. Hence, our findings suggest that predictive return regressions using final revised macroeconomic data are mis-specified. 


\subsection{Further Evidence Based on Mincer-Zarnowitz Regressions}

In the previous section we documented that future revisions to macroeconomic time series contain predictive information about bond returns. While this is an interesting result, it is not conclusive about the real-time predictability of bond returns since investors might partly anticipate future revisions. In this subsection, we thus address the question whether it is the component of revisions that is predictable in real time or the unpredictable component of revisions that mainly drives their forecasting ability.

We do this in the following simple way. We first run individual in-sample regressions of the final revised values of each series in our panel on various specifications of information sets that investors could have used in real time to predict the final numbers. This is similar in spirit to the regressions suggested by Mincer and Zarnowitz (1969) in order to assess the precision of forecasts. We therefore refer to these as Mincer-Zarnowitz regressions. For each specification of the information set that was potentially available to investors in real time, we then collect the predicted value and the residual of the final revised series. Applying the principal component loadings from the final revised series then allows us to break the final revised factor $f_{1 t \mid T}$ down into the time- $t$ predictable and unpredictable components. Finally, we regress the one-year holding period returns on these two components.

The results of this exercise are provided in Table 5. The upper (lower) panel uses as dependent variable the excess holding period return on a two-year (five-year) Treasury note. The first column shows the median adjusted $R^{2}$ across all 68 Mincer-Zarnowitz regressions and the number in brackets below reports the cross-sectional standard deviation of adjusted $R^{2}$ 's. Columns one through five provide the estimates and corresponding $t$-statistics for the different regressors: a constant, the two yield spreads S31 and S54, as well as the time-t predictable and the unpredictable components of the final revised factor.

The rows show different specifications of the information sets potentially available to investors in real time. For each specification, we report regression results using i) only the predictable component of the final revised data, ii) only the unpredictable component, and iii) using both jointly. The first specification employs only the real-time observations on all series to predict their final revised counterparts. The first column reports the median (5\%) and standard deviation (8\%) of the adjusted $R^{2}$ 's of the 68 Mincer-Zarnowitz regressions. Hence, relatively small shares of the final revised data are predictable using the real-time observations alone. Not surprisingly, the last two elements in this row show that only the unpredictable part of the final revised data but not the predicted carries forecasting power for bond returns in this specification. Of course, in practice investors do not only observe new data releases but also the revisions to prior months' announcements. Since we have shown revisions to be serially correlated, these might help to predict future revisions.

In the third specification, we therefore augment the information set with the time- $t$ observations of the cumulative prior twelve months' revisions. Moreover, we augment the hypothetical information set with a number of financial market indicators observed in real 
time. These are the time-t observations of the one-year excess holding period returns for the 2-, 3-, 4-, and 5-year maturity which we use as dependent variables, as well as a set of commonly used equity risk factors: the three Fama and French (1993) factors MKT, HML, and SMB, as well as a momentum factor, a short-term reversal, and a long-term reversal factor, all from Ken French's website. Despite using this rich set of financial market information, the predictability of the final revised data does not increase materially and the unforecastable component of the final revised data remains the one driving the predictability of future bond returns.

Ideally, we would run these Mincer-Zarnowitz regressions using market participants' realtime expectations of the final revised observations for all series. Unfortunately, such a rich data set is not available. However, as a proxy we can use survey data from professional forecasters for a number of related variables. If the variables that survey participants are asked to forecast share common dynamics with the series in our panel, then such survey data might help to predict the final revised series. We therefore assemble a comprehensive monthly data set on consensus survey forecasts for a range of economic indicators and forecast horizons, see Section 3. The first five principal components of these series explain more than $95 \%$ of the variation common to all survey forecasts. We use these five principal components in addition to the real-time data and the financial market indicators to predict each individual final revised series in our panel and then decompose the predictive information of $f_{1 t \mid T}$ into its predictable and unpredictable component as of period $t$. The results are provided in the bottom three rows of each panel. For the two-year maturity they indicate that the survey data improve the fit of the final revised data somewhat. The coefficient on the predicted component now becomes significant at the $10 \%$ level and the adjusted $R^{2}$ is slightly higher for the unpredictable component. For the five year maturity, however, the predictable component remains insignificant and the unpredictable component continues to imply a larger adjusted $R^{2}$. On balance these results indicate that while some of the predictive power for bond returns contained in future revisions could have been anticipated by investors in real time, a significant fraction of the forecasting power found in final revised macroeconomic data is spuriously driven by unpredictable future revisions.

\subsection{Out-of-Sample Analysis}

In this section we analyze whether the in-sample results discussed above carry over to an out-of-sample setting. Specifically, we run the following exercise. Starting in January 1995, we extract the first principal component from the revised and real-time versions of our data set of 68 macroeconomic variables using data from March 1982 through the month when the forecast is made. We then run three regressions of the individual bond returns on (i) a constant (ii) a constant and the twelve month lag of the predictor variable, and (iii) a constant, the lagged predictor as well as the two yield spreads S31 and S54. For 
each of these specifications, we use the estimated regression coefficients to predict excess bond returns twelve months out and record the corresponding forecast errors. We then assess whether the macroeconomic information significantly improves forecast accuracy by computing the ratio of mean squared forecast errors (MSE) of the unrestricted models which add the macro information divided by the MSE of the restricted models (i.e. specifications which only use a constant or a constant and the yield spreads). To assess whether a given macroeconomic factor significantly improves predictability with respect to the benchmark model, we report the ENC-NEW test for nested models suggested by Clark and McCracken (2001). We further test for all specifications that are not based on the final revised factor whether they are significantly outperformed by the model using the final revised factor $f_{1 t \mid T}$. To this end, we report the Diebold and Mariano (1995) statistic (DM) of equal predictive power for non-nested models.

The two vertical panels of Table 6 summarize the results using two benchmark models: one with only a constant (left panel) and one using a constant and the two yield spreads (right panel). As before, the two horizontal panels show analogous regression results for the two-year and five-year Treasury notes. The first row in each of the two horizontal panels reports the forecast results using the first principal component of final revised data $f_{1 t \mid T}$ as the predictor variable. Comparing the out-of-sample predictions based on a constant and this factor with those of a rolling mean model in the left-hand panel, we see that it reduces forecast errors by $5 \%$ and $4 \%$ for the two-year and five-year maturities, respectively. According to the ENC-NEW test these MSE reductions are statistically significant at the five percent level for both maturities. The improvement is even stronger when we control for the information contained in contemporaneous bond prices. Adding $f_{1 t \mid T}$ to the model that includes a constant, S31 and S54, the mean squared forecast error drops by $13 \%$ for the two-year and 11\% for the five-year Treasury. Not surprisingly, these large reductions in mean-squared forecast errors are found to be highly statistically significant according to the ENC-NEW statistic.

In line with our in-sample regressions we next look at the out-of-sample forecast results using a pseudo real-time factor which we obtain by weighting the real-time observations on all 68 series by the principal component loadings from the final revised data through period $t$ (second row). We also directly estimate a real-time factor, $f_{1 t-1 \mid t}$, as the first principal component extracted from all series' observations available through period $t$ (third row). Both have very similar out-of-sample forecast performance, as shown by the MSE ratios relative to the rolling mean and the model including the two yield spreads. While the realtime factors do not contain significant predictive information beyond the sample mean of returns, they do carry some predictive power in conjunction with the information in the yield curve. Indeed, as indicated by the ENC-NEW statistics both the pseudo real-time factor and the true real-time factor reduce squared forecast errors significantly with respect to the model with only a constant and the yield spreads. However, the significantly negative 
Diebold-Mariano statistics also indicate that both real-time factors have less predictive power for future bond returns than the final revised factor. Thus, there is at best weak out-ofsample evidence for predictive information in real-time macroeconomic data. Moreover, the final revised factor significantly outperforms the models based on real-time information only.

In row four of Table 6 we separately study the out-of-sample performance of a model using as predictor the revision component of the final revised factor. Precisely, we apply the principal components loadings of the final revised data estimated through period $t$ to the data revisions of the 68 series in our panel. As indicated by the Clark-McCracken statistics, for both maturities this factor significantly outperforms the nested restricted model using only a constant (left panel) or a constant and the two yield spreads (right panel). Moreover, the Diebold-Mariano statistics show that the revision factor does not predict bond returns with less precision than the final revised factor. Hence, data revisions carry predictive power for future bond returns also out-of-sample. As before, we can further break down the cumulative revisions into those arising in the first year after the initial release and those further out. If bond investors incorporate the information contained in revisions into bond prices then the former component can affect the one-year holding period returns that we study whereas the latter by construction cannot. Rows five and six of the table document the out-of-sample forecast performance of the two revision components. The mean squared error ratios show that both components significantly reduce the forecast errors with respect to the two benchmark models by similar amounts, and significantly so as indicated by the Clark-McCracken tests. This finding reinforces our in-sample results which showed that a sizeable fraction of the documented predictability from final revised data is driven by the data revisions they contain.

In the previous section we have shown that information contained in real-time survey forecasts of macroeconomic conditions helped to explain some but not all of the information in final revised series that is informative about future bond returns. In rows seven and eight of Table 6 we assess whether the survey information also directly helps to predict future bond returns, both individually and in conjunction with the information contained in our real-time macroeconomic data set. In row seven we use the first principal component from all available projections contained in the Blue Chip survey to predict future bond returns. We label this factor $f_{1 t}^{B C}$. This factor significantly reduces forecast errors with respect to the model using only a constant, but does not improve forecasting performance with respect to the benchmark model which also uses two yield spreads as predictors. ${ }^{6}$ In the last row of the table we combine the real-time factor $f_{1 t-1 \mid t}$ with the survey forecast factor $f_{1 t}^{B C}$. For the two-year maturity this augmented model predicts bond returns significantly better than

\footnotetext{
${ }^{6}$ Note that the ENC-NEW statistic rejects the null of equal predictive ability in favor of the model including the survey forecast factor for the two-year maturity even though it implies a larger mean squared forecast error than the spreads only. The likely explanation is that the larger model may be less accurate than the smaller model due to imprecisely estimated parameters in the finite sample whereas the asymptotic distribution of the test statistic is about equal forecast accuracy at population values.
} 
both benchmark models. For the five-year maturity, the augmented model only outperforms the benchmark model containing no yield curve information and performs worse with respect to the benchmark model that does include the two yield spreads as regressors.

To summarize, the results in this section confirm our findings from the in-sample analysis. While real-time macroeconomic data appear to contain some predictive information for future Treasury returns, the amount of predictability suggested using final revised data is strongly overstated. Instead, a significant fraction of the forecasting power of macro factors for bond returns is captured by the revision components.

\subsection{Analysis Using Nonfarm Payroll Employment}

One interpretation of our findings thus far is that the predictability for bond returns found in revised macroeconomic data is to a large degree spurious. An alternative interpretation is that the proxies for investors' information set that we have employed do not adequately recover the information investors actually have available to predict bond returns in real time. In particular, investors' forecasts of the first releases of key macroeconomic indicators may be informative both about future bond returns as well as about future data revisions. In this section, we explore this possibility by explicitly conditioning on investors' forecasts for a key macroeconomic release: non-farm private payroll employment. 7 Precisely, we first repeat the predictive bond return regressions using the final revised and real-time observations of non-farm payroll employment as regressors, in each case controlling for market participants' consensus expectations right before the initial release. We then study the yield curve's reaction to announcements of payroll employment.

\subsubsection{Predictive Return Regressions with Nonfarm Payroll Employment}

Table 7 provides the results for in-sample predictive bond return regressions using the monthto-month change in private non-farm payroll employment as predictor variable. The top (bottom) panel documents the results for the two-year (five-year) maturity. As before, we proxy for the information contained in contemporaneous bond yields by using the S31 and S54 spreads as additional regressors. Moreover, in order to explicitly account for market participants' expectations relative to the actual release, we add the surprise component of the consensus survey expectation (i.e. the simple difference between the first release and the consensus expectation) for non-farm payroll as a regressor. The first column in both panels provides the results of a benchmark regression where we only use the two yield spreads and the surprise component as regressors. The coefficients on all three are highly statistically significant and the adjusted $R^{2}$ 's are $17 \%$ (20\%) for the two-year (five-year) maturity. In the second column, we add the final revised value of non-farm payroll as a regressor. For both

\footnotetext{
${ }^{7}$ Nonfarm payroll employment is arguably the most important macroeconomic release for bond investors, see e.g. Jones, Lamont, and Lumsdaine (1998) or Fleming and Remolona (1999))
} 
maturities, the corresponding coefficient is highly significant with $t$-statistics above 6 (4) for the two-year (five-year) maturity and the adjusted $R^{2}$ jumps considerably, to $37 \%$ and $30 \%$ for the two- and five-year maturity, respectively.

Since we have found little incremental information in the publication lag component with predictive regressions involving factors, we abstract from this component here and instead focus our attention on the differences in predictive ability between the first release and the revised observations of nonfarm payroll employment growth. In the third column we replace the final revised observation by the first released observation. While the coefficients on the first release remain statistically significant, the adjusted $R^{2}$ 's drop considerably, indicating that there is less predictive information contained in the first release of non-farm payroll employment than in the final revised number. In the fourth column, we explicitly assess the predictive information contained in the revision component. For both maturities, the revisions are found to be strongly significant predictors of future bond returns, even when controlling for the information contained in market prices and in market expectations about payroll employment. In the last column, we regress one-year bond returns jointly on the first release and the revision component of final revised payroll growth. While the coefficients on both are significantly different from zero, the coefficients on the revision component are more than twice as large in absolute value than the ones for the first release component. Recall that the coefficients ought to be the same under the hypothesis that investors used the final data to predict bond returns. As before, we explicitly test for the equality of the two coefficients using a simple F-test (see the discussion in Section 2). The test rejects the null hypothesis of equal coefficients at high confidence levels.

In sum, the results in this section confirm the factor-based evidence in the previous sections which have indicated that a large share of the predictive power for future bond returns contained in macroeconomic variables is due to the revision components, unknown to investors in real-time. Hence, predictive regressions using final revised data likely suffer from mis-specification biases.

\subsubsection{The Yield Curve's Reaction to Nonfarm Payroll Announcements}

We now study the reaction of the Treasury yield curve to non-farm private payroll announcements, controlling for investors' predictions of the release. This section closely follows the analysis in Gilbert (2011) who shows that the return on the S\&P500 index on days of payroll announcements predicts future revisions with a positive sign in expansions and a negative sign in recessions. This is interpreted as evidence that equity investors care about the final revised figure of payroll employment more than about the first release. In the context of our findings thus far, his results could be interpreted in the following way. When observing a new macroeconomic data release investors update their beliefs, incorporate the new information into prices and at the same time correctly anticipate the future revisions. We now assess whether similar effects might be at work in the Treasury market. While Jones, Lamont, and 
Lumsdaine (1998) and Fleming and Remolona (1999), among others, have documented the importance of non-farm private payroll employment announcements for Treasuries, to the best of our knowledge no prior paper has studied the relationship between payroll announcement returns in the Treasury market and future data revisions.

Table 8 shows an in-sample regression of daily changes in the level, slope and curvature of the Treasury yield curve on days of payroll news announcements on a number of explanatory variables. The sample for this regression is again 1990:01-2007:12. The yield curve factors have been obtained as the first three principal components of Treasury yields of maturities ranging from one through 20 years published in the Federal Reserve's H.15 release. Combined, they explain about $99 \%$ of the total variance of the yields in the panel.

The explanatory variables are a constant, the median expectation from a survey of market participants $\left(N F P_{t \mid t-1}\right)$, the first release $\left(N F P_{t \mid t+1}\right)$, the revision to the prior month's release $\left(N F P_{t-1 \mid t+1}-N F P_{t-1 \mid t}\right)$, the revision to the release made two months ago $\left(N F P_{t-2 \mid t+1}-\right.$ $\left.N F P_{t-2 \mid t}\right)$, and the sum of all future revisions to the current release $\left(N F P_{t \mid T}-N F P_{t \mid t+1}\right)$. The upper panel reports the full sample results, the bottom two panels repeat the regressions for expansion and recession samples separately $\left.\right|^{8}$

We begin by considering the full sample regressions, summarized in the upper panel of the table. The first row shows that the yield curve level strongly reacts to the surprise component of payroll releases as the coefficient on the consensus forecast is close in absolute value to the coefficient on the actual release and both coefficients are highly statistically significant. Hence, the level of the yield curve shifts up significantly when the actual payroll release exceeds the market expectation. As shown in the second row, the slope of the Treasury term structure also increases somewhat with positive news about the current pace of payroll growth, independently of the market expectation. The curvature (third row) is unaffected by the announcement in the full sample.

Interestingly, while considerably smaller than the reaction to the surprise component, the coefficient on the revision to the prior month's release is statistically significant (column four), suggesting that revisions also affect the level of Treasury yields but not the slope or the curvature. The revision to the release two months ago (column five) has a small statistically significant impact on the yield curve slope in the full sample. More importantly, the final sample revisions reported in the last column do not drive any of the announcement day yield changes in the full sample. Hence, controlling for past revisions and contemporaneous surprises, the yield curve reaction to payroll news does not anticipate future revisions.

At first sight, the latter result is consistent with the findings of Gilbert (2011) who documents a statistically insignificant coefficient on future revisions in similar regressions using the daily change of the S\&P 500 index as dependent variable. Splitting the sample into expansion and recession periods, however, he finds statistically significant and offsetting

\footnotetext{
${ }^{8}$ These have been determined by whether the announcement date falls into an NBER recession or expansion.
} 
effects: stock returns react positively to future revisions in expansions and negatively in recessions. Looking at the middle and bottom panel of Table 8, we do not see a strong impact of future revisions on the yield curve components in either subsample. While changes to the yield curve level are slightly negatively correlated with future revisions in recessions, there is essentially no relationship in expansions. Moreover, the yield curve slope and curvature do not show a significant correlation with future revisions in expansions or recessions. Hence, the announcement day regressions do not provide strong evidence supporting the view that investors correctly anticipate future revisions when they see the initial announcement.

While future revisions do not appear to be incorporated into bond prices on days of payroll announcements, past revisions affect bond yields significantly. Looking at the coefficients of the prior month's revision $\left(N F P_{t-1 \mid t+1}-N F P_{t-1 \mid t}\right)$, and the revision of the first release two months earlier, $\left(N F P_{t-2 \mid t+1}-N F P_{t-2 \mid t}\right)$, we see that both are strongly significant in recessions. Hence, the information contained in revisions to past releases is incorporated into bond prices, especially in recessions. This is in line with our earlier findings that revisions occurring in the first year after the initial announcement drive a fair amount of the predictive power for bond returns contained in final revised macro data.

\section{Discussion and Concluding Remarks}

In this paper, we have revisited the predictive ability of macroeconomic factors for bond returns taking into account the real-time nature of macroeconomic information. We have shown that a sizeable fraction of the in-sample and out-of-sample predictive ability of macroeconomic variables for future Treasury returns is driven by data revisions. Decomposing data revisions into those occurring during the first year after the initial release and those at later times, we report that a fraction of the predictive information in final revised data is due to revisions being incorporated into prices over the first few months after the initial release. More specifically, studying the yield curve reaction to non-farm payroll news we find that bond investors incorporate recent revisions into bond prices but do not seem to anticipate future revisions when pricing in the new information.

In addition to revisions occurring in the first few months after the initial release, bond returns are also correlated with revisions reported more than one year after the initial release which by construction cannot directly affect the one-year holding period returns that we study. This is surprising as these revisions often capture re-estimated seasonal factors based on more recent data. Our results thus suggest that these revisions may be informative for bond yields. Seasonal factors from standard adjustment methods have long been perceived as not being insulated from recessions. In a recent paper Wright (2013) documents that seasonal and cyclical variation in economic time series is often confounded due to estimation biases in seasonal filters. Wright (2013) further provides evidence for predictability of revisions in seasonal factors. While he does not use financial market data to predict the revisions of 
seasonals, our findings indicate that bond returns might be helpful in this regard.

A few recent papers (see, for example, Joslin, Priebsch, and Singleton (2010), Duffee (2011), Wright (2011)) have argued that macroeconomic factors that are not or only weakly spanned by the cross-section of Treasury yields are drivers of Treasury risk premia. These studies commonly use final revised macroeconomic data to capture the information set available to investors. Our results show that a sizeable fraction of the predictive content of macroeconomic factors for excess bond returns depends on the revision component comprised in revised macroeconomic time series. Albeit considerably weaker, we have also found evidence for predictability using real-time macroeconomic data. We interpret this as suggesting that weakly spanned macroeconomic risk factors have some role in predicting future bond yields also in real time.

Our results suggest a number of avenues for future research. First, as noted before, the factors extracted from a set of revised macroeconomic data do not span the same space as the factors extracted from the real-time data. However, the use of revised data to extract factors is prevalent in the literature. Only a handful of papers, including Christoffersen, Ghysels, and Swanson (2002) and Gilbert (2011), acknowledge the importance of properly aligning data releases when studying the macroeconomic sources of return predictability. The construction of real-time factors is therefore of independent interest.

Second, given prior evidence on the predictive power of macroeconomic factors for conditional first and second moments of stock returns (e.g. Ludvigson and $\mathrm{Ng}(2007)$ ) it would be interesting to see how much of this predictability 'survives' in real time.

Finally, since data revisions have different time series properties than real-time data, it appears fruitful to further analyze the predictability of final revised macroeconomic time series by decomposing them into their real-time and revision components. We leave these questions for future research. 


\section{References}

Adrian, T., R. K. Crump, and E. Moench, 2013, "Pricing the term structure with linear regressions," Journal of Financial Economics, 110, 110-138.

Andersen, T. G., T. Bollerslev, F. X. Diebold, and C. Vega, 2003, "Micro effects of macro announcements: Real-time price discovery in foreign exchange," American Economic Review, 93, 38-62.

Ang, A., and M. Piazzesi, 2003, "A no-arbitrage vector autoregression of term structure dynamics with macroeconomic and latent variables," Journal of Monetary Economics, 50, 745-787.

Aruoba, S., 2008, "Data revisions are not well behaved," Journal of Money, Credit and Banking, 40, 319-340.

Barillas, F., 2013, "Can we exploit predictability in bond markets?," Working Paper, Emory University.

Beber, A., M. Brandt, and M. Luisi, 2013, "Economic cycles and expected stock returns," working paper, CEPR Discussion Papers.

Berkson, J., 1950, "Are there two regressions?," Journal of the American Statistical Association, 45, 164-180.

Boyd, J. H., J. Hu, and R. Jagannathan, 2005, "The stock market's reaction to unemployment news: Why bad news is usually good for stocks," Journal of Finance, 60(2), 649-672.

Campbell, J. Y., and R. J. Shiller, 1991, "Yield spreads and interest rate movements: A bird's eye view," Review of Economic Studies, 58, 495-514.

Chen, N., R. Roll, and S. Ross, 1986, "Economic forces and the stock market," Journal of Business, 59, 383-403.

Christoffersen, P., E. Ghysels, and N. Swanson, 2002, "Let's get 'real' about using economic data," Journal of Empirical Finance, 9, 343-360.

Clark, T., and M. McCracken, 2001, "Tests of equal forecast accuracy and encompassing for nested models," Journal of Econometrics, 105, 85-110.

Cochrane, J., and M. Piazzesi, 2005, "Bond risk premia," American Economic Review, 95, 138-160. 
Croushore, D., 2006, "Forecasting with real-time macroeconomic data," in Handbook of Economic Forecasting, ed. by G. Elliott, C. Granger, and A. Timmermann, vol. 1, pp. 961-982. Elsevier.

Croushore, D., and C. L. Evans, 2006, "Data revisions and the identification of monetary policy shocks," Journal of Monetary Economics, 53, 1135-1160.

Croushore, D., and T. Stark, 2001, "A real-time data set for macroeconomists," Journal of Econometrics, 105, 111-130.

Diebold, F. X., and R. S. Mariano, 1995, "Comparing predictive accuracy," Journal of Business and Economic Statistics, 13, 253-263.

Duffee, G., 2011, "Information in (and not in) the term structure," Review of Financial Studies, 24, 2895-2934.

Durbin, J., 1954, "Errors in variables," Revue de l'Institut International de Statistique, 22, $23-32$.

Ehrmann, M., and M. Fratzscher, 2005, "Exchange rates and fundamentals: New evidence from real-time data," Journal of International Money and Finance, 24, 317-341.

Fama, E., and R. Bliss, 1987, "The information in long-maturity forward rates," American Economic Review, 77, 680-692.

Fama, E. F., and K. R. French, 1993, "Common risk factors in the returns on stocks and bonds," Journal of Financial Economics, 33, 3-56.

Favero, C. A., L. Niu, and L. Sala, 2012, "Term Structure Forecasting: No-Arbitrage Restrictions versus Large Information Set," Journal of Forecasting, 31, 124-156.

Fleming, M. J., and E. M. Remolona, 1999, "Price formation and liquidity in the US Treasury market: The response to public information," Journal of Finance, 54, 1901-1915.

Ghysels, E., and D. R. Osborn, 2001, The econometric analysis of seasonal time series. Cambridge University Press, New York.

Gilbert, T., 2011, "Information aggregation around macroeconomic announcements: Revisions matter," Journal of Financial Economics, 101, 114-131.

Guo, H., 2003, "On the real-time forecasting ability of the consumption-wealth ratio," Federal Reserve Bank of St. Louis Working Paper Series.

Jacobs, J., and S. Van Norden, 2011, "Modeling data revisions: Measurement error and dynamics of true values," Journal of Econometrics, 161, 101-109. 
Jones, C. M., O. Lamont, and R. L. Lumsdaine, 1998, "Macroeconomic news and bond market volatility," Journal of Financial Economics, 47, 315-337.

Joslin, S., M. Priebsch, and K. Singleton, 2010, "Risk premiums in dynamic term structure models with unspanned macro risks," Working Paper, Stanford University.

Joslin, S., K. Singleton, and H. Zhu, 2011, "A new perspective on Gaussian dynamic term structure models," Review of Financial Studies, 24, 926-970.

Koenig, E., S. Dolmas, and J. Piger, 2003, "The use and abuse of real-time data in economic forecasting," Review of Economics and Statistics, 85, 618-628.

Lettau, M., and S. Ludvigson, 2001, "Consumption, aggregate wealth, and expected stock returns," Journal of Finance, 56, 815-849.

Ludvigson, S., and S. Ng, 2007, "The empirical risk-return relation: A factor analysis approach," Journal of Financial Economics, 83, 171-222.

Ludvigson, S., and S. Ng, 2009, "Macro factors in bond risk premia," Review of Financial Studies, 22, 5027-5067.

Ludvigson, S., and S. Ng, 2011, "A factor analysis of bond risk premia," in Handbook of Empirical Economics and Finance, ed. by A. Ulah, and D. Giles, pp. 313-372. Chapman and Hall.

Mankiw, N. G., D. E. Runkle, and M. D. Shapiro, 1984, "Are preliminary announcements of the money stock rational forecasts?," Journal of Monetary Economics, 14, 15-27.

Mincer, J. A., and V. Zarnowitz, 1969, "The evaluation of economic forecasts," in Economic Forecasts and Expectations: Analysis of Forecasting Behavior and Performance. NBER, pp. $1-46$.

Moench, E., 2008, "Forecasting the yield curve in a data-rich environment: A no-arbitrage factor-augmented VAR approach," Journal of Econometrics, 146, 26-43.

Molodtsova, T., A. Nikolsko-Rzhevskyy, and D. H. Papell, 2008, "Taylor rules with real-time data: A tale of two countries and one exchange rate," Journal of Monetary Economics, 55, S63-S79.

Orphanides, A., 2001, "Monetary policy rules based on real-time data," American Economic Review, 91, 964-985.

Orphanides, A., and S. van Norden, 2002, "The unreliability of output-gap estimates in real time," Review of Economics and Statistics, 84, 569-583. 
Runkle, D. E., 1998, "Revisionist history: How data revisions distort economic policy research," Federal Reserve Bank of Minneapolis Quarterly Review, 22, 3-12.

Sargent, T. J., 1989, "Two models of measurements and the investment accelerator," Journal of Political Economy, 97, 251-287.

Stark, T., and D. Croushore, 2002, "Forecasting with a real-time data set for macroeconomists," Journal of Macroeconomics, 24, 507-531.

Swanson, N., E. Ghysels, and M. Callan, 1999, "A multivariate time series analysis of the data revision process for industrial production and the composite leading indicator," in Cointegration, Causality and Forecasting - A Festschrift in Honour of Clive W. J. Granger, ed. by R. Engle, and H. White. Oxford University Press.

Wright, J., 2011, "Term premia and inflation uncertainty: Empirical evidence from an international panel dataset," American Economic Review, 101, 1514-1534.

Wright, J. H., 2013, "Unseasonal Seasonals?," Brookings Papers on Economic Activity, forthcoming. 


\section{Tables and Figures}

\section{Table 1: Summary Statistics for Publication Lags and Revision Components}

This table provides summary statistics and regression $R^{2} \mathrm{~s}$ for the publication lag and revision components comprised in the 68 time series of our macroeconomic data set. For each of the statistics, the cross-sectional mean, standard deviation, median, min, and max are shown across the 68 variables in our panel of macroeconomic time series. 'Publication Lag' refers to the average number of days it takes from the end of the calendar month it measures until the first release of a series is published. 'Variance Ratio' denotes the ratio of the variance of the pure revision component (i.e. ignoring the publication lag) and the variance of the final revised series. 'AR(1) Coefficient of $\nu_{i t}$ ' refers to the estimated first-order autoregressive coefficient associated with the revision component. ' $R^{2}: \nu_{i t}$ on $f_{1 t}^{\nu}$ ' is the $R^{2}$ obtained from a regression of the individual revision components on the first principal component extracted from all revision components, $f_{1 t}^{\nu}$ ' $R^{2}: x_{i t}$ on $f_{1 t}^{R V}$, is the $R^{2}$ obtained from a regression of the individual final revised series on the first principal component extracted from our set of 68 final revised macroeconomic time series. ' $R^{2}: x_{i t}$ on $f_{1 t}^{L N}$, denotes the $R^{2}$ obtained from a regression of the individual final revised series on the first principal component extracted from the data set used by Ludvigson and $\mathrm{Ng}$ (2009) which comprises both final revised macroeconomic as well as financial time series.

\begin{tabular}{lrrrrr}
\hline \hline & Mean & StDev & Median & Min & Max \\
\hline Publication Lag & 12.749 & 9.182 & 12.971 & 4.842 & 35.106 \\
Variance Ratio & 0.677 & 0.722 & 0.412 & 0.091 & 4.685 \\
AR $(1)$ Coefficient of $\nu_{i t}$ & -0.435 & 0.197 & -0.489 & -0.684 & 0.106 \\
$R^{2}: \nu_{i t}$ on $f_{1 t}^{\nu}$ & 0.088 & 0.155 & 0.013 & 0.000 & 0.673 \\
$R^{2}: x_{i t}$ on $f_{1 t}^{R V}$ & 0.151 & 0.240 & 0.011 & 0.000 & 0.845 \\
$R^{2}: x_{i t}$ on $f_{1 t}^{L N}$ & 0.172 & 0.204 & 0.106 & 0.000 & 0.725 \\
\hline \hline
\end{tabular}




\section{Table 2: Correlation with Ludvigson and Ng (2011) Factors}

This table shows the pairwise correlations between the set of factors which Ludvigson and $\mathrm{Ng}$ (2011) find have the strongest predictive power for bond returns, and the first eight principal components extracted from our revised and real-time macroeconomic data set, respectively. The Ludvigson and $\mathrm{Ng}$ factors are labeled with a superscript $L N$, the principal components extracted from our revised data set are indicated by a subscript $t \mid T$, and the principal components extracted from our real-time data set are labeled with a subscript $t-1 \mid t$. The LN2 factors have been extracted from data covering the sample period 1964-2007. The revised and real-time factors have been extracted from monthly data covering the period 1982:03-2007:12. The correlations have been computed over that sample period.

\begin{tabular}{lrcrr} 
& $f_{1 t}^{L N}$ & $f_{8 t}^{L N}$ & $\left(f_{5 t}^{L N}\right)^{2}$ & $\left(f_{1 t}^{L N}\right)^{3}$ \\
\hline \hline & \multicolumn{4}{c}{ Revised Factors } \\
\hline$f_{1 t \mid T}$ & 0.853 & 0.140 & -0.323 & 0.606 \\
$f_{2 t \mid T}$ & 0.032 & -0.101 & -0.051 & 0.034 \\
$f_{3 t \mid T}$ & -0.038 & -0.102 & 0.170 & -0.047 \\
$f_{4 t \mid T}$ & -0.011 & -0.141 & -0.001 & 0.001 \\
$f_{5 t \mid T}$ & -0.013 & -0.165 & 0.029 & 0.005 \\
$f_{6 t \mid T}$ & 0.034 & -0.168 & 0.019 & 0.050 \\
$f_{7 t \mid T}$ & 0.059 & -0.277 & -0.053 & 0.020 \\
$f_{8 t \mid T}$ & -0.003 & 0.071 & 0.024 & -0.039 \\
\hline & & & \\
\hline$f_{1 t-1 \mid t}$ & 0.552 & 0.128 & -0.179 & -0.397 \\
$f_{2 t-1 \mid t}$ & -0.140 & 0.050 & -0.034 & 0.045 \\
$f_{3 t-1 \mid t}$ & 0.055 & -0.051 & 0.025 & 0.088 \\
$f_{4 t-1 \mid t}$ & 0.065 & -0.014 & -0.050 & -0.094 \\
$f_{5 t-1 \mid t}$ & -0.057 & -0.064 & 0.066 & 0.046 \\
$f_{6 t-1 \mid t}$ & 0.030 & 0.059 & -0.097 & 0.027 \\
$f_{7 t-1 \mid t}$ & -0.032 & 0.050 & 0.043 & 0.002 \\
$f_{8 t-1 \mid t}$ & -0.030 & 0.080 & -0.018 & \\
\hline \hline
\end{tabular}




\section{Table 3: In-Sample Bond Return Prediction}

This table shows regression results for predictive bond return regressions of the form

$$
r x_{t+12}^{(n)}=\alpha_{n}+\beta_{1 n}^{\prime} S 31_{t}+\beta_{1 n}^{\prime} S 54_{t}+\gamma_{n}^{\prime} F_{t}^{I}+\epsilon_{t+12}^{(n)},
$$

where $r x_{t+12}^{(n)}$ denotes the one-year excess holding period return on an $n$-year bond, $S 31_{t}$ is the spread between the three-year and the one-year yield, and $S 54_{t}$ the spread between the five-year and the four-year yield. Factors with the superscript $L N$ have been extracted from the Ludvigson and $\mathrm{Ng}$ (2011) panel of revised macroeconomic and financial variables. $f_{1 t \mid T}$ denotes the first principal component extracted from our panel of 68 revised macroeconomic time series; $f_{1 t-1 \mid t}$ is the first principal component of the real-time observations of the same 68 time series. The sample period is 1982:03-2007:12. The $t$-statistics in parentheses are based on Newey-West standard errors with a maximum lag of 18 months. The two panels present results for excess returns on 2-, and 5 -year bonds, respectively. ${ }^{*}, * *, * *$ denote significance at the 10,5 , and $1 \%$ level, respectively.

\begin{tabular}{|c|c|c|c|c|c|c|c|c|c|c|c|c|}
\hline & cst & S31 & S54 & $f_{1 t}^{L N}$ & $\left(f_{1 t}^{L N}\right)^{3}$ & $\left(f_{5 t}^{L N}\right)^{2}$ & $f_{8 t}^{L N}$ & $\begin{array}{l}f_{1 t \mid T} \\
\end{array}$ & $\left(f_{1 t \mid T}\right)^{3}$ & $f_{1 t-1 \mid t}$ & $\left(f_{1 t-1 \mid t}\right)^{3}$ & R2adj \\
\hline \multicolumn{13}{|c|}{ One-year excess holding return on 2-year Treasury } \\
\hline \multirow[t]{2}{*}{$\overline{(1)}$} & 0.51 & $1.91^{* * *}$ & $-5.68 * * *$ & & & & & & & & & 0.18 \\
\hline & {$[1.35]$} & {$[3.85]$} & {$[-4.59]$} & & & & & & & & & \\
\hline \multirow[t]{2}{*}{$(2)$} & 0.48 & $1.89^{* * *}$ & $-5.27 * * *$ & $-0.50 * * *$ & & & & & & & & 0.28 \\
\hline & {$[1.50]$} & {$[3.51]$} & {$[-3.76]$} & {$[-3.11]$} & & & & & & & & \\
\hline \multirow[t]{2}{*}{$(3)$} & 0.41 & $1.98^{* * *}$ & $-5.81 * * *$ & $-0.66^{* * *}$ & $0.05^{* *}$ & $0.13^{*}$ & 0.06 & & & & & 0.29 \\
\hline & {$[1.26]$} & {$[4.49]$} & {$[-4.86]$} & {$[-3.13]$} & {$[2.44]$} & {$[1.80]$} & {$[0.62]$} & & & & & \\
\hline \multirow[t]{2}{*}{ (4) } & 0.53 & $1.94^{* * *}$ & $-5.89 * * *$ & & & & & $-0.14^{* *}$ & & & & 0.26 \\
\hline & {$[1.56]$} & {$[3.56]$} & {$[-4.06]$} & & & & & {$[-2.30]$} & & & & \\
\hline \multirow[t]{2}{*}{ (5) } & 0.44 & $1.96^{* * *}$ & $-6.26 * * *$ & & & $0.14^{*}$ & 0.02 & $-0.17^{* *}$ & $0.00^{*}$ & & & 0.27 \\
\hline & {$[1.26]$} & {$[4.00]$} & {$[-4.44]$} & & & {$[1.96]$} & {$[0.16]$} & {$[-2.38]$} & {$[1.91]$} & & & \\
\hline \multirow[t]{2}{*}{ (6) } & 0.54 & $1.96^{* * *}$ & $-6.16^{* * *}$ & & & & & & & $-0.09^{*}$ & & 0.21 \\
\hline & [1.48] & [3.83] & {$[-4.94]$} & & & & & & & {$[-1.66]$} & & \\
\hline \multirow{2}{*}{$(7)$} & 0.38 & $1.93^{* * *}$ & $-6.28 * * *$ & & & $0.20^{* *}$ & 0.03 & & & -0.09 & 0.00 & 0.23 \\
\hline & [1.05] & {$[4.17]$} & {$[-5.00]$} & & & {$[2.40]$} & {$[0.29]$} & & & {$[-1.36]$} & {$[0.77]$} & \\
\hline \multirow{3}{*}{ (1) } & & & & One-yea & excess $\mathrm{h}$ & lding ret & irn on & -year Tre & sury & & & \\
\hline & 0.61 & $6.70^{* * *}$ & $-16.82^{* * *}$ & & & & & & & & & 0.19 \\
\hline & {$[0.59]$} & {$[3.85]$} & {$[-3.82]$} & & & & & & & & & \\
\hline \multirow[t]{2}{*}{$(2)$} & 0.55 & $6.66^{* * *}$ & $-15.99 * * *$ & $-1.02^{* * *}$ & & & & & & & & 0.23 \\
\hline & {$[0.58]$} & {$[3.61]$} & {$[-3.38]$} & {$[-2.80]$} & & & & & & & & \\
\hline \multirow[t]{2}{*}{ (3) } & 0.14 & $7.05^{* * *}$ & $-17.97 * * *$ & $-1.34^{* *}$ & $0.14^{*}$ & $0.55^{* *}$ & 0.45 & & & & & 0.25 \\
\hline & {$[0.15]$} & {$[4.60]$} & {$[-4.60]$} & {$[-2.52]$} & {$[1.87]$} & {$[2.42]$} & [1.31] & & & & & \\
\hline \multirow[t]{2}{*}{ (4) } & 0.65 & $6.78^{* * *}$ & $-17.38^{* * *}$ & & & & & $-0.36 * * *$ & & & & 0.24 \\
\hline & {$[0.70]$} & {$[3.62]$} & {$[-3.60]$} & & & & & {$[-2.82]$} & & & & \\
\hline \multirow[t]{2}{*}{ (5) } & 0.23 & $6.96^{* * *}$ & $-18.48^{* * *}$ & & & $0.48 * *$ & 0.36 & $-0.37^{* *}$ & 0.00 & & & 0.25 \\
\hline & {$[0.25]$} & {$[4.17]$} & {$[-4.21]$} & & & [2.09] & [1.03] & {$[-2.26]$} & {$[1.24]$} & & & \\
\hline \multirow[t]{2}{*}{ (6) } & 0.68 & $6.81^{* * *}$ & $-17.90^{* * *}$ & & & & & & & -0.20 & & 0.21 \\
\hline & {$[0.68]$} & {$[3.87]$} & {$[-4.17]$} & & & & & & & {$[-1.49]$} & & \\
\hline \multirow[t]{2}{*}{ (7) } & 0.09 & $6.88^{* * *}$ & $-18.33^{* * *}$ & & & $0.64^{* *}$ & 0.42 & & & -0.13 & -0.00 & 0.23 \\
\hline & {$[0.09]$} & [4.29] & {$[-4.65]$} & & & {$[2.50]$} & {$[1.16]$} & & & {$[-0.71]$} & {$[-0.17]$} & \\
\hline
\end{tabular}




\section{Table 4: In-Sample Decomposition of Bond Return Predictability}

This table shows regression results for predictive bond return regressions of the form

$$
r x_{t+12}^{(n)}=c_{n}+\beta_{1 n}^{\prime} S 31_{t}+\beta_{1 n}^{\prime} S 54_{t}+\gamma_{n}^{\prime} F_{t}^{I}+\epsilon_{t+12}^{(n)},
$$

where $r x_{t+12}^{(n)}$ denotes the one-year excess holding period return on an $n$-year bond, $S 31_{t}$ is the spread between the three-year and the one-year yield, $S 54_{t}$ between the five-year and the four-year yield. $F_{t}^{I}$ denotes the oneyear lagged observations of a factor extracted from one of several different data sets. $F_{t}^{I}=\hat{\Lambda}^{\prime} X_{t \mid T}$ is the first principal component extracted from our panel of 68 revised macroeconomic time series; $F_{t}^{I}=\hat{\Lambda}^{\prime} X_{t \mid t+1}$ applies the loadings of the first principal component of final revised series to the cross-section of first release observations of all series; $F_{t}^{I}=\hat{\Lambda}^{\prime} X_{t-1 \mid t}$ applies the final revised principal component loadings to the cross-section of realtime observations; $F_{t}^{I}=\hat{\Lambda}^{\prime}\left(X_{t \mid t+1}-X_{t-1 \mid t}\right)$ refers to the corresponding linear combination of publication lag components; $F_{t}^{I}=\hat{\Lambda}^{\prime}\left(X_{t \mid T}-X_{t \mid t+1}\right)$ denotes the linear combination of full sample revisions of all series; $F_{t}^{I}=$ $\hat{\Lambda}^{\prime}\left(X_{t \mid t+13}-X_{t \mid t+1}\right)$ refers to the corresponding linear combination of revisions made over the first year after the initial release; $F_{t}^{I}=\hat{\Lambda}^{\prime}\left(X_{t \mid T}-X_{t \mid t+13}\right)$ denotes the linear combination of all revisions occurring more than one year after the initial release. The sample period is 1982:03-2007:12. Regression intercepts are not reported to conserve space. The $t$-statistics in parentheses are based on Newey-West standard errors with a maximum lag of 18 months. The two panels present results for excess returns on 2-, and 5-year bonds, respectively. *, **, *** denote significance at the 10,5 , and $1 \%$ level, respectively.

\begin{tabular}{|c|c|c|c|c|c|c|c|c|c|}
\hline & $(1)$ & $(2)$ & $(3)$ & $(4)$ & $(5)$ & $(6)$ & $(7)$ & $(8)$ & $(9)$ \\
\hline & & One & ear excess & holding return & on 2-year & Treasury & & & \\
\hline \multirow[t]{2}{*}{$\overline{\operatorname{cst}}$} & 0.51 & 0.53 & 0.52 & 0.54 & 0.51 & 0.50 & 0.52 & 0.49 & 0.52 \\
\hline & {$[1.35]$} & {$[1.56]$} & {$[1.42]$} & {$[1.47]$} & {$[1.35]$} & {$[1.39]$} & {$[1.39]$} & {$[1.35]$} & {$[1.60]$} \\
\hline \multirow[t]{2}{*}{ S31 } & $1.91 * * *$ & $1.94^{* * *}$ & $1.90 * * *$ & $1.97^{* * *}$ & $1.91 * * *$ & $1.96 * * *$ & $1.89 * * *$ & $1.97 * * *$ & $1.98 * * *$ \\
\hline & [3.85] & {$[3.56]$} & [3.56] & [3.90] & {$[3.86]$} & {$[4.23]$} & [3.89] & {$[4.08]$} & [3.91] \\
\hline \multirow[t]{2}{*}{ S54 } & $-5.68 * * *$ & $-5.89 * * *$ & $-5.70 * * *$ & $-6.21^{* * *}$ & $-5.71 * * *$ & $-5.85 * * *$ & $-5.64 * * *$ & $-5.86 * * *$ & $-6.04 * * *$ \\
\hline & {$[-4.59]$} & {$[-4.06]$} & {$[-4.17]$} & {$[-5.03]$} & {$[-4.55]$} & {$[-5.05]$} & {$[-4.72]$} & {$[-4.79]$} & {$[-4.53]$} \\
\hline \multirow[t]{2}{*}{$\hat{\Lambda}^{\prime} X_{t \mid T}$} & & $-0.14^{* *}$ & & & & & & & \\
\hline & & {$[-2.30]$} & & & & & & & \\
\hline \multirow[t]{2}{*}{$\hat{\Lambda}^{\prime} X_{t \mid t+1}$} & & & -0.07 & & & & & & \\
\hline & & & {$[-1.29]$} & & & & & & \\
\hline \multirow[t]{2}{*}{$\hat{\Lambda}^{\prime} X_{t-1 \mid t}$} & & & & -0.08 & & & & & $-0.13 * *$ \\
\hline & & & & {$[-1.61]$} & & & & & {$[-2.08]$} \\
\hline \multirow{2}{*}{$\hat{\Lambda}^{\prime}\left(X_{t \mid t+1}-X_{t-1 \mid t}\right)$} & & & & & 0.00 & & & & $-0.14^{* * *}$ \\
\hline & & & & & {$[0.48]$} & & & & {$[-2.86]$} \\
\hline \multirow{2}{*}{$\hat{\Lambda}^{\prime}\left(X_{t \mid T}-X_{t \mid t+1}\right)$} & & & & & & $-0.15^{* *}$ & & & $-0.28^{* * *}$ \\
\hline & & & & & & {$[-2.53]$} & & & {$[-3.45]$} \\
\hline \multirow[t]{2}{*}{$\hat{\Lambda}^{\prime}\left(X_{t \mid t+13}-X_{t \mid t+1}\right)$} & & & & & & & $-0.17^{* *}$ & & \\
\hline & & & & & & & {$[-2.31]$} & & \\
\hline \multirow[t]{2}{*}{$\hat{\Lambda}^{\prime}\left(X_{t \mid T}-X_{t \mid t+13}\right)$} & & & & & & & & $-0.13^{* *}$ & \\
\hline & & & & & & & & {$[-2.05]$} & \\
\hline R2adj & 0.18 & 0.26 & 0.20 & 0.21 & 0.18 & 0.21 & 0.19 & 0.20 & 0.28 \\
\hline F-stat & & & & & & & & & $6.76^{* * *}$ \\
\hline \multirow[t]{2}{*}{ p-val } & & & & & & & & & 0.00 \\
\hline & & One & ar excess & holding return & on 5-year & Treasury & & & \\
\hline \multirow[t]{2}{*}{$\overline{c s t}$} & 0.61 & 0.65 & 0.63 & 0.68 & 0.61 & 0.58 & 0.64 & 0.56 & 0.60 \\
\hline & {$[0.59]$} & {$[0.70]$} & {$[0.63]$} & {$[0.68]$} & {$[0.60]$} & {$[0.59]$} & {$[0.63]$} & {$[0.56]$} & {$[0.67]$} \\
\hline \multirow[t]{2}{*}{ S31 } & $6.70 * * *$ & $6.78^{* * *}$ & $6.69^{* * *}$ & $6.84^{* * *}$ & $6.71 * * *$ & $6.85^{* * *}$ & $6.62^{* * *}$ & $6.87 * * *$ & $6.90^{* * *}$ \\
\hline & [3.85] & [3.62] & [3.64] & [3.91] & {$[3.86]$} & {$[4.16]$} & [3.93] & {$[4.01]$} & {$[3.93]$} \\
\hline \multirow[t]{2}{*}{ S54 } & $-16.82 * * *$ & $-17.38 * * *$ & $-16.88^{* * *}$ & $-18.03^{* * *}$ & $-16.88^{* * *}$ & $-17.36^{* * *}$ & $-16.69^{* * *}$ & $-17.34 * * *$ & $-17.56^{* * *}$ \\
\hline & {$[-3.82]$} & {$[-3.60]$} & {$[-3.64]$} & {$[-4.20]$} & {$[-3.76]$} & {$[-4.12]$} & {$[-3.93]$} & {$[-3.94]$} & {$[-3.96]$} \\
\hline$\hat{\Lambda}^{\prime} X_{t \mid T}$ & & $\begin{array}{r}-0.36 * * * \\
{[-2.82]}\end{array}$ & & & & & & & \\
\hline \multirow[t]{2}{*}{$\hat{\Lambda}^{\prime} X_{t \mid t+1}$} & & & -0.15 & & & & & & \\
\hline & & & {$[-1.28]$} & & & & & & \\
\hline \multirow[t]{2}{*}{$\hat{\Lambda}^{\prime} X_{t-1 \mid t}$} & & & & -0.17 & & & & & $-0.32 * *$ \\
\hline & & & & {$[-1.55]$} & & & & & {$[-2.26]$} \\
\hline \multirow[t]{2}{*}{$\hat{\Lambda}^{\prime}\left(X_{t \mid t+1}-X_{t-1 \mid t}\right)$} & & & & & 0.01 & & & & $-0.38 * * *$ \\
\hline & & & & & {$[0.35]$} & & & & {$[-3.82]$} \\
\hline \multirow[t]{2}{*}{$\hat{\Lambda}^{\prime}\left(X_{t \mid T}-X_{t \mid t+1}\right)$} & & & & & & $-0.46 * *$ & & & $-0.85^{* * *}$ \\
\hline & & & & & & {$[-2.46]$} & & & {$[-3.93]$} \\
\hline \multirow[t]{2}{*}{$\hat{\Lambda}^{\prime}\left(X_{t \mid t+13}-X_{t \mid t+1}\right)$} & & & & & & & $-0.61 * * *$ & & \\
\hline & & & & & & & {$[-2.92]$} & & \\
\hline$\hat{\Lambda}^{\prime}\left(X_{t \mid T}-X_{t \mid t+13}\right)$ & & & & & & & & $-0.38^{*}$ & \\
\hline & & & & & & & & {$[-1.85]$} & \\
\hline R2adj & 0.19 & 0.24 & 0.20 & 0.20 & 0.19 & 0.22 & 0.20 & 0.21 & 0.26 \\
\hline$\overline{\text { F-stat }}$ & & & & & & & & & $7.91^{* * *}$ \\
\hline p-val & & & & & & & & & 0.00 \\
\hline
\end{tabular}




\section{Table 5: Mincer-Zarnowitz Decomposition of Final Revised Series}

This table provides in-sample regression results for predictive bond return regressions of the form

$$
\begin{aligned}
r x_{t+12}^{(n)} & =\alpha_{n}+\beta_{1 n}^{\prime} S 31_{t}+\beta_{2 n}^{\prime} S 54_{t}+\gamma_{n}^{\prime} F_{t}^{z_{t}}+\delta_{n}^{\prime} F_{t}^{\eta_{t \mid T}}+\epsilon_{t+12}^{(n)}, \\
X_{i t \mid T} & =a_{i}+b_{i}^{\prime} z_{i t}+\eta_{i t \mid T}, \\
F_{t}^{z_{t}} & =\hat{\Lambda}_{Z}^{\prime}\left(\hat{b}^{\prime} z_{t}\right), \\
F_{t}^{\eta_{t \mid T}} & =\hat{\Lambda}_{\eta}^{\prime} \hat{\eta}_{t \mid T}
\end{aligned}
$$

where $r x_{t+12}^{(n)}$ denotes the one-year excess holding period return on an $n$-year bond. median $\left(\bar{R}_{i}^{2}\right)$ refers to the median of adjusted $R^{2}$ 's across all 68 Mincer-Zarnowitz regressions. The number in brackets below reports the cross-sectional standard deviation of adjusted $R^{2}$ 's. $S 31_{t}$ is the spread between the threeyear and the one-year yield, $S 54_{t}$ between the five-year and the four-year yield. $F_{t}^{z_{t}}$ denotes the one-year lagged observations of a factor constructed as the weighted average of the real-time predictable components of all series in our panel of 68 final revised macroeconomic variables; $F_{t}^{\eta_{t \mid T}}$ refers to the corresponding component of residuals. In both cases, the weights are given by the loadings of the first principal component extracted from our final revised panel. The different rows correspond to different assumptions about the information sets $z_{i t}$ available to investors in real time. $X_{t-1 \mid t}$ only uses the real-time observations of each series; $\left\{X_{t-1 \mid t}, X_{t-1 \mid t}-X_{t-13 \mid t}\right.$, Fin $\left._{t}\right\}$ uses real-time observations as well as the cumulative revision over the prior year and a number of financial market indicators observed in real time; $\left\{X_{t-1 \mid t}, B C_{t}\right\}$ uses the real-time observation as well as the first five principal components of consensus forecasts from the Blue Chip Economic Indicators survey for a range of macroeconomic and financial indicators from one-quarter to fourquarters ahead; $\left\{X_{t-1 \mid t}, X_{t-1 \mid t}-X_{t-13 \mid t}\right.$, Fin $\left._{t}, B C_{t}\right\}$ comprises the real-time, past revision, financial market indicator and the survey forecasts. The sample period is 1982:03-2007:12. The $t$-statistics in parentheses are based on Newey-West standard errors with a maximum lag of 18 months. The two panels present results for excess returns on 2 - and 5 -year bonds. ${ }^{*},{ }^{* *},{ }^{* * *}$ denote significance at the 10,5 , and $1 \%$ level, respectively.

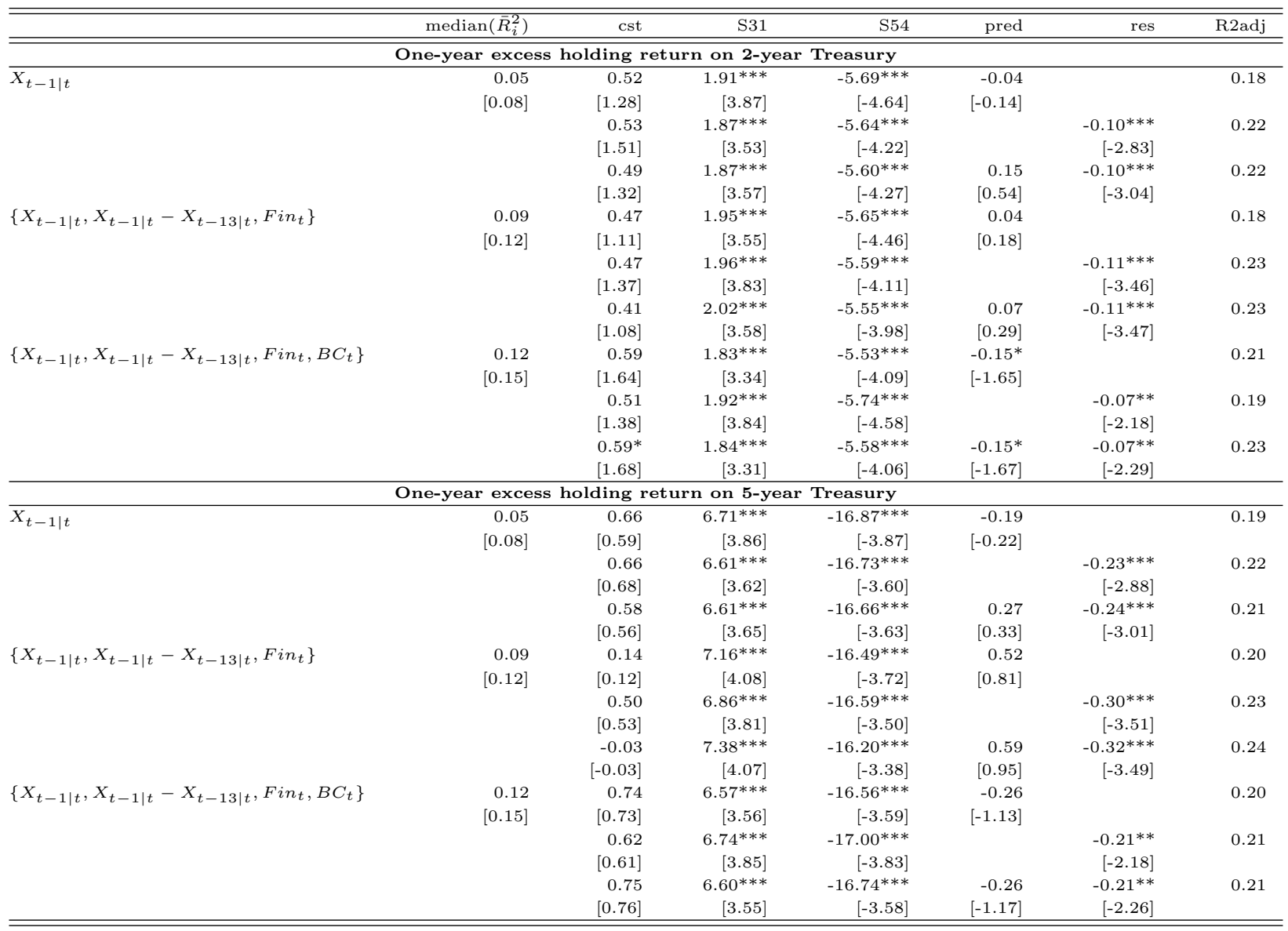




\section{Table 6: Out-of-Sample Assessment of Bond Return Predictability}

This table provides out-of-sample forecast results for predictive bond return regressions of the form

$$
r x_{t+12}^{(n)}=\alpha_{n}+\beta_{n}^{\prime} Z_{t}+\gamma_{n}^{\prime} F_{t}^{I}+\epsilon_{t+12}^{(n)},
$$

where $r x_{t+12}^{(n)}$ denotes the one-year excess holding period return on an $n$-year bond, $Z_{t}$ denotes a vector of yield spreads, and $F_{t}^{I}$ denotes the one-year lagged observations of a vector of factors extracted from various macroeconomic data sets. $f_{1 t \mid T}$ is the first principal component extracted from the final revised observations of all the 68 variables in our panel of US macroeconomic variables; $\hat{\Lambda}^{\prime} X_{t \mid t}$ applies the loadings of the first principal component of final revised data to the real-time observations of all series; $f_{1 t-1 \mid t}$ denotes the first principal component extracted from the real-time observations of all series using information only through period $t ; \hat{\Lambda}^{\prime}\left(X_{t \mid T}-X_{t \mid t+1}\right)$ applies the loadings of the first principal component of final revised data to the full-sample revisions of all 68 series; $\hat{\Lambda}^{\prime}\left(X_{t \mid t+13}-X_{t \mid t+1}\right)$ is the component related to the revisions over the first year after the initial release; $\hat{\Lambda}^{\prime}\left(X_{t \mid T}-X_{t \mid t+13}\right)$ captures the component of $f_{1 t \mid T}$ that is related to all future revisions more than one year out; $f_{1 t}^{B C}$ is the first principal component of consensus forecasts for various macroeconomic and financial time series and horizons from one through four quarters ahead collected from the Blue Chip Economic Indicators survey; $\left\{f_{1 t-1 \mid t}, f_{1 t}^{B C}\right\}$ combines the first principal component of real-time observation of the 68 series in our panel with the first principal component of all consensus forecasts from the Blue Chip survey. The first three columns do not include additional regressors. The fourth through sixth column include the spread between the three-year and the one-year yield, $S 31_{t}$, and the spread between the five-year and the four-year yield, $S 54_{t}$, as additional regressors. $\frac{M S E u}{M S E r}$ denotes the ratio of mean squared forecast error variances from a (unrestricted) model that uses a macroeconomic factor as regressor versus a (restricted) model that does not. ENC-NEW denotes Clark and McCracken (2001)'s ENC-NEW test of equal forecast accuracy for nested models. $D M$ is the Diebold-Mariano (1995) statistic for equal forecast performance of all models relative to the one using the first principal component of final revised data. The two horizontal panels present results for excess returns on 2- and 5-year bonds, respectively. The training sample is from 1982:03-1994:12. From 1995:01 through 2006:12, all principal components and predictive regressions are reestimated month by month and forecasts of one-year excess holding period returns are made. $*, * *, * * *$ denote significance at the 10,5 , and $1 \%$ level.

\begin{tabular}{|c|c|c|c|c|c|c|c|}
\hline & & \multicolumn{3}{|c|}{ Benchmark model: constant only } & \multicolumn{3}{|c|}{ Benchmark model: constant, $S 31$, and $S 54$} \\
\hline & & $\frac{M S E_{u}}{M S E_{r}}$ & ENC-NEW & $\mathrm{DM}$ & $\frac{M S E_{u}}{M S E_{r}}$ & ENC-NEW & $\mathrm{DM}$ \\
\hline \multicolumn{8}{|c|}{ One-year excess holding return on 2-year Treasury } \\
\hline$(1)$ & $f_{t \mid T}$ & 0.95 & $8.66^{* *}$ & & 0.87 & $18.04^{* *}$ & \\
\hline$(2)$ & $\hat{\Lambda}^{\prime} X_{t-1 \mid t}$ & 1.01 & 0.67 & $-1.81^{*}$ & 0.97 & $3.84^{* *}$ & $-3.57^{* * *}$ \\
\hline$(3)$ & $f_{t-1 \mid t}$ & 1.01 & 0.47 & $-2.03^{* *}$ & 0.98 & $3.61^{* *}$ & $-3.86^{* * *}$ \\
\hline$(4)$ & $\hat{\Lambda}^{\prime}\left(X_{t \mid T}-X_{t \mid t+1}\right)$ & 0.93 & $7.15^{* *}$ & 0.34 & 0.90 & $9.97^{* *}$ & -1.00 \\
\hline$(5)$ & $\hat{\Lambda}^{\prime}\left(X_{t \mid t+13}-X_{t \mid t+1}\right)$ & 0.97 & $3.13^{* *}$ & -0.32 & 0.97 & $3.23 * *$ & $-2.27^{* *}$ \\
\hline$(6)$ & $\hat{\Lambda}^{\prime}\left(X_{t \mid T}-X_{t \mid t+13}\right)$ & 0.94 & $5.86^{* *}$ & 0.12 & 0.91 & $9.20^{* *}$ & -1.10 \\
\hline$(7)$ & $f_{t}^{B C}$ & 0.87 & $27.26^{* *}$ & 0.30 & 1.01 & $10.76^{* *}$ & -0.64 \\
\hline$(8)$ & $\left\{f_{t-1 \mid t}, f_{t}^{B C}\right\}$ & 0.83 & $31.44^{* *}$ & 0.54 & 0.92 & $17.43^{* *}$ & -0.31 \\
\hline \multicolumn{8}{|c|}{ One-year excess holding return on 5-year Treasury } \\
\hline$(1)$ & $f_{t \mid T}$ & 0.96 & $5.95^{* *}$ & & 0.89 & $13.56^{* *}$ & \\
\hline$(2)$ & $\hat{\Lambda}^{\prime} X_{t-1 \mid t}$ & 1.01 & -0.38 & -1.10 & 0.98 & $1.93^{* *}$ & $-2.47^{* * *}$ \\
\hline$(3)$ & $f_{t-1 \mid t}$ & 1.01 & -0.48 & $-1.19^{*}$ & 0.98 & $1.90^{* *}$ & $-2.56^{* * *}$ \\
\hline$(4)$ & $\hat{\Lambda}^{\prime}\left(X_{t \mid T}-X_{t \mid t+1}\right)$ & 0.94 & $7.34^{* *}$ & 0.51 & 0.91 & $10.11^{* *}$ & -0.64 \\
\hline$(5)$ & $\hat{\Lambda}^{\prime}\left(X_{t \mid t+13}-X_{t \mid t+1}\right)$ & 0.96 & $4.15^{* *}$ & -0.02 & 0.96 & $4.04^{* *}$ & $-1.76^{* *}$ \\
\hline$(6)$ & $\hat{\Lambda}^{\prime}\left(X_{t \mid T}-X_{t \mid t+13}\right)$ & 0.96 & $5.06^{* *}$ & 0.07 & 0.92 & $8.47^{* *}$ & -0.86 \\
\hline$(7)$ & $f_{t}^{B C}$ & 0.96 & $11.45^{* *}$ & 0.02 & 1.07 & -1.23 & -1.16 \\
\hline$(8)$ & $\left\{f_{t-1 \mid t}, f_{t}^{B C}\right\}$ & 0.95 & $12.14^{* *}$ & 0.08 & 1.03 & 1.00 & -1.15 \\
\hline
\end{tabular}




\section{Table 7: Predicting Bond Returns with Non-farm Payroll Employment}

This table shows regression results for predictive bond return regressions of the form

$$
r x_{t+12}^{(n)}=\alpha_{n}+\beta_{1 n}^{\prime} S 31_{t}+\beta_{2 n}^{\prime} S 54_{t}+\beta_{3 n}\left(N F P_{t \mid t+1}-N F P_{t \mid t-1}\right)+\gamma_{n}^{\prime} N F P_{t}^{I}+\epsilon_{t+12}^{(n)},
$$

where $r x_{t+12}^{(n)}$ denotes the one-year excess holding period return on an $n$-year bond, $S 31_{t}$ is the spread between the three-year and the one-year yield, $S 54_{t}$ between the five-year and the four-year yield. $N F P_{t \mid t+1}-N F P_{t \mid t-1}$ denotes the surprise component of the new announcement with $N F P_{t \mid t-1}$ being the market consensus expectation. $N F P_{t}^{I}$ denotes the one-year lagged observations of several different components of non-farm private payroll data. $N F P_{t \mid T}$ is the final revised payroll data; $N F P_{t \mid t+1}$ is the first release of payroll data for month $t$; and $N F P_{t \mid T}-N F P_{t \mid t+1}$ is the full sample revision. The sample period is 1990:01-2007:12. Regression intercepts are not reported to conserve space. The $t$-statistics in parentheses are based on Newey-West standard errors with a maximum lag of 18 months. The two panels present results for excess returns on two- and five-year bonds. *, **, *** denote significance at the 10, 5, and $1 \%$ level, respectively.

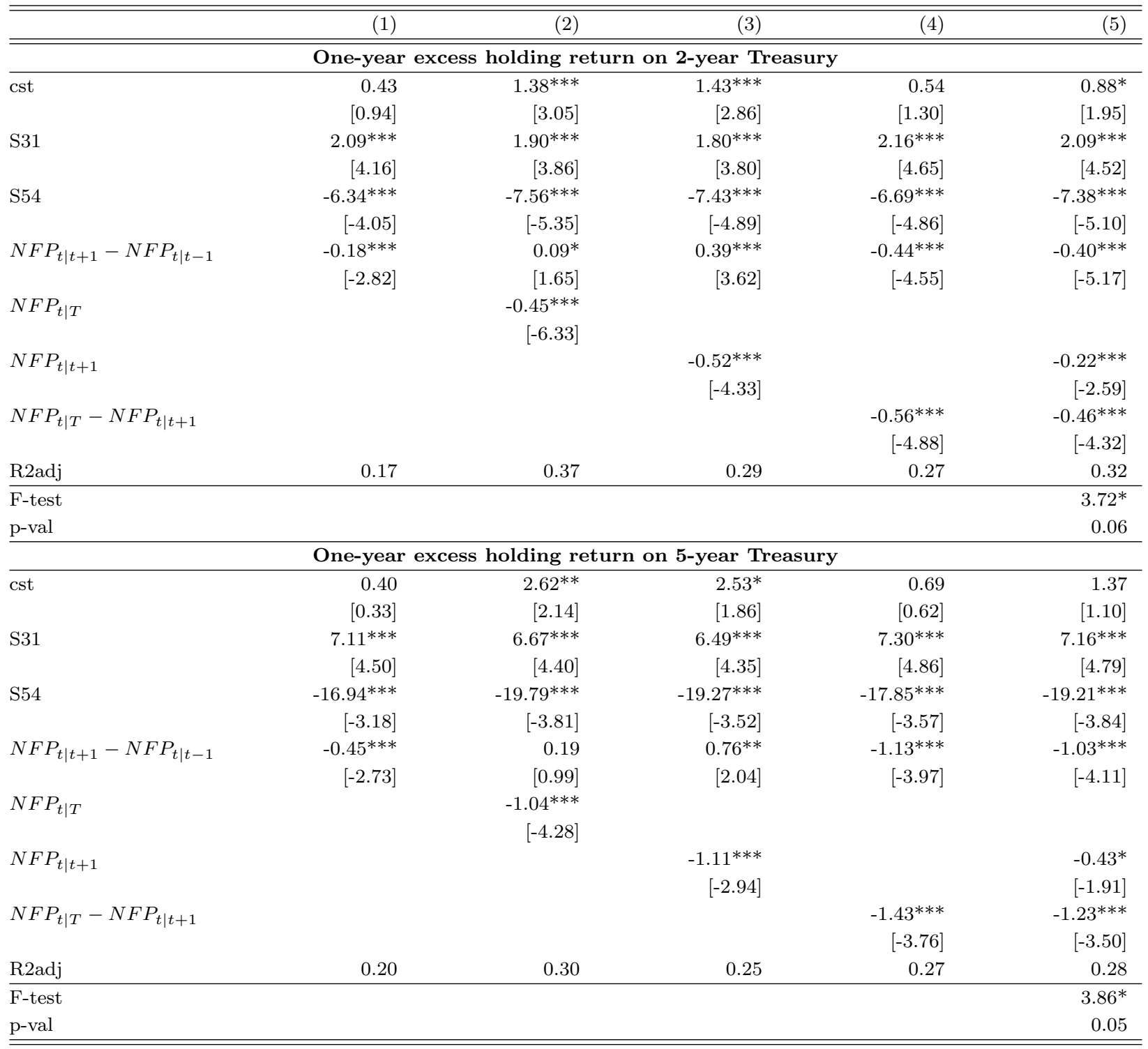




\section{Table 8: Treasury Yield Curve Reaction to Non-farm Payroll News}

This table shows regression results for predictive bond return regressions of the form

$$
\begin{aligned}
\Delta P C_{j t}= & \alpha_{j}+\beta_{j}^{1} N F P_{t \mid t-1}+\beta_{j}^{2} N F P_{t \mid t+1}+\beta_{j}^{3}\left(N F P_{t-1 \mid t+1}-N F P_{t-1 \mid t}\right) \ldots \\
& +\beta_{j}^{4}\left(N F P_{t-2 \mid t+1}-N F P_{t-2 \mid t}\right)+\beta_{j}^{5}\left(N F P_{t \mid T}-N F P_{t \mid t+1}\right)+\epsilon_{j t} .
\end{aligned}
$$

$\triangle P C_{j t}$ denote the daily change of the first three principal components of constant maturity Treasury yields on 1-, 2-, 3-, 7-, 10-, and 20-year Treasury securities from the H.15 release on days of payroll announcements. $N F P_{t \mid t-1}$ is the consensus forecast for payroll growth from the Money Market Services database before 1999 and from Bloomberg after 1999; $N F P_{t \mid t+1}$ denotes the first released data; $N F P_{t-1 \mid t+1}-X_{t-1 \mid t}$ and $N F P_{t-2 \mid t+1}-N F P_{t-2 \mid t}$ refer to the revisions of the prior two months released with the new announcement. $N F P_{t \mid T}-N F P_{t \mid t+1}$ denotes the cumulative revision made after the first release. The sample period is 1990:01-2007:12. The top panel shows the full-sample results. The bottom two panels repeat the regressions for announcements falling into expansion and

\begin{tabular}{|c|c|c|c|c|c|c|c|}
\hline & $(1)$ & $(2)$ & $(3)$ & $(4)$ & $(5)$ & $(6)$ & $(7)$ \\
\hline & cst & $N F P_{t \mid t-1}$ & $N F P_{t \mid t+1}$ & $N F P_{t-1 \mid t+1}-N F P_{t-1 \mid t}$ & $N F P_{t-2 \mid t+1}-N F P_{t-2 \mid t}$ & $N F P_{t \mid T}-N F P_{t \mid t+1}$ & R2adj \\
\hline \multicolumn{8}{|c|}{ Full Sample $(\mathrm{N}=276)$} \\
\hline \multirow[t]{2}{*}{$\triangle P C_{1}$} & $0.18^{* * *}$ & $-0.67 * * *$ & $0.54^{* * *}$ & $0.29 * * *$ & 0.20 & 0.05 & 0.32 \\
\hline & {$[3.80]$} & {$[-7.72]$} & {$[7.16]$} & {$[2.59]$} & {$[1.35]$} & {$[0.91]$} & \\
\hline \multirow[t]{2}{*}{$\triangle P C_{2}$} & -0.06 & -0.09 & $0.26^{* * *}$ & 0.02 & $-0.37^{*}$ & -0.04 & 0.12 \\
\hline & {$[-0.69]$} & {$[-0.76]$} & {$[2.61]$} & {$[0.17]$} & {$[-1.92]$} & {$[-0.58]$} & \\
\hline \multirow[t]{2}{*}{$\triangle P C_{3}$} & 0.04 & -0.04 & -0.00 & -0.18 & 0.05 & 0.03 & -0.01 \\
\hline & {$[0.57]$} & {$[-0.34]$} & {$[-0.01]$} & {$[-1.35]$} & {$[0.25]$} & {$[0.53]$} & \\
\hline \multicolumn{8}{|c|}{ Expansion Sample $(N=238)$} \\
\hline \multirow[t]{2}{*}{$\Delta P C_{1}$} & $0.15^{* *}$ & $-0.65^{* * *}$ & $0.54^{* * *}$ & $0.23^{* *}$ & $0.40^{* *}$ & 0.07 & 0.32 \\
\hline & {$[2.15]$} & {$[-7.91]$} & {$[6.46]$} & {$[2.09]$} & {$[2.30]$} & {$[1.34]$} & \\
\hline \multirow[t]{2}{*}{$\triangle P C_{2}$} & -0.04 & -0.04 & $0.23^{* *}$ & 0.00 & $-0.53^{*}$ & -0.04 & 0.11 \\
\hline & {$[-0.40]$} & {$[-0.29]$} & {$[1.96]$} & {$[0.02]$} & {$[-1.92]$} & {$[-0.53]$} & \\
\hline \multirow[t]{2}{*}{$\triangle P C_{3}$} & 0.01 & -0.15 & 0.11 & 0.04 & 0.01 & 0.11 & -0.01 \\
\hline & {$[0.05]$} & {$[-0.98]$} & {$[0.94]$} & {$[0.26]$} & {$[0.06]$} & {$[1.25]$} & \\
\hline \multicolumn{8}{|c|}{ Recession Sample $(\mathrm{N}=38)$} \\
\hline \multirow[t]{2}{*}{$\overline{\Delta P C_{1}}$} & -0.25 & $-0.55^{* * *}$ & $0.41^{* * *}$ & $0.56^{* * *}$ & $-0.28^{* *}$ & $-0.20^{*}$ & 0.43 \\
\hline & {$[-1.57]$} & {$[-2.68]$} & {$[2.62]$} & {$[3.84]$} & {$[-2.51]$} & {$[-1.76]$} & \\
\hline \multirow[t]{2}{*}{$\triangle P C_{2}$} & -0.15 & $-0.42^{* * *}$ & $0.43^{* * *}$ & $0.16^{*}$ & 0.36 & -0.13 & 0.10 \\
\hline & {$[-0.89]$} & {$[-4.71]$} & {$[4.48]$} & {$[1.80]$} & {$[0.79]$} & {$[-0.75]$} & \\
\hline \multirow[t]{2}{*}{$\triangle P C_{3}$} & -0.23 & $0.56^{* *}$ & $-0.57 * * *$ & $-0.94 * * *$ & 0.22 & -0.16 & 0.27 \\
\hline & {$[-1.30]$} & [2.01] & {$[-2.94]$} & {$[-11.08]$} & {$[0.41]$} & {$[-1.57]$} & \\
\hline
\end{tabular}
recession periods as defined by the NBER. *, **, *** denote significance at the 10, 5, and $1 \%$ level, respectively. 


\section{Figure 1: Factor Comparison - Revised versus Real-time}

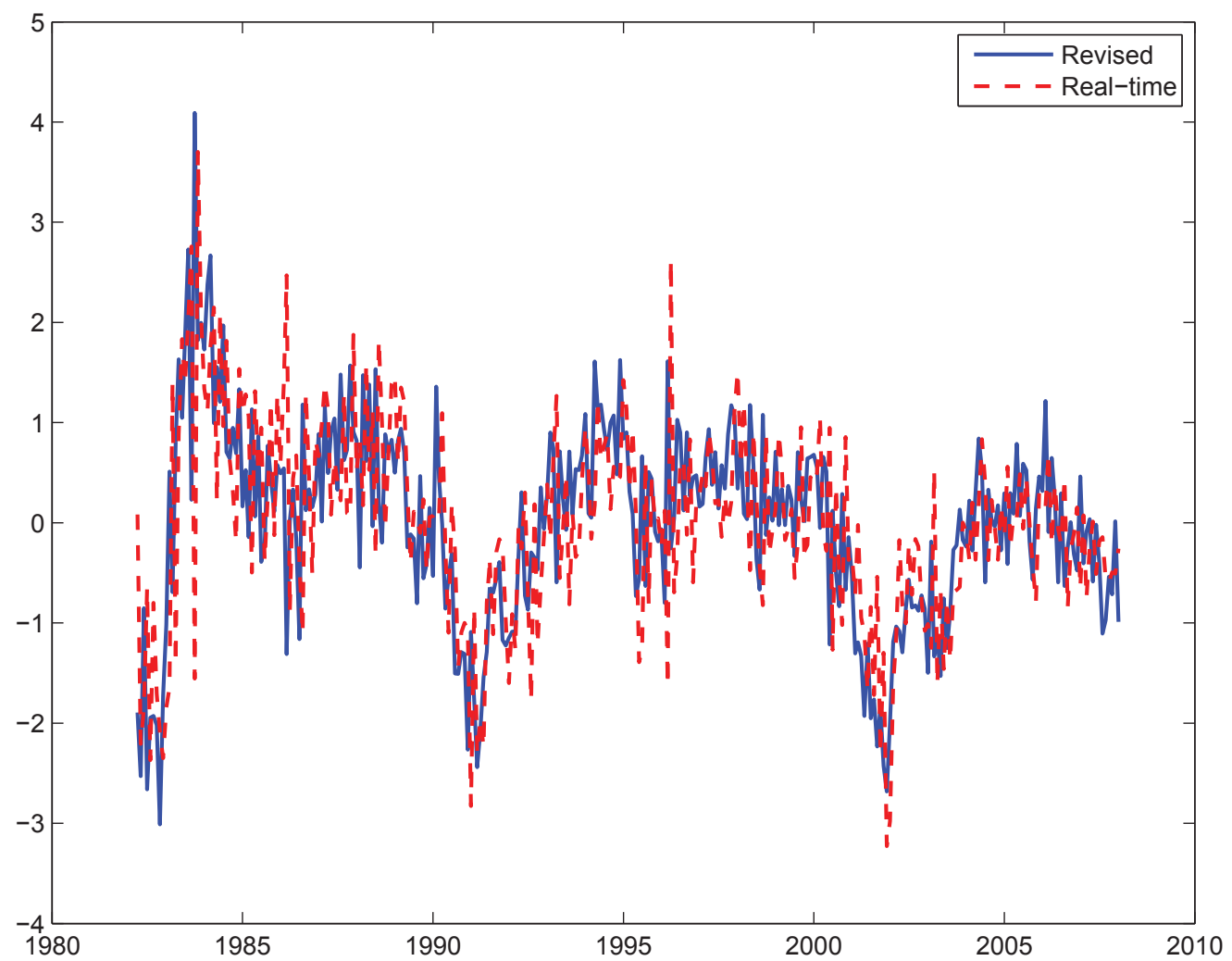

This figure plots the first principal component extracted from a panel of 68 revised macroeconomic time series, $f_{1 t \mid T}$, along with the first principal component extracted from the corresponding set of real-time data, $f_{1 t \mid t}$. The sample period is 1982:03-2007:12. 


\section{A Data Appendix}

This appendix lists the 68 macroeconomic time series used in our analysis. 'TCode' provides the transformation applied to each series. TCode $=1$ denotes monthly differences, TCode $=2$ monthly growth rates and TCode $=3$ first differences of monthly growth rates. 'Start Date' provides the date of the first available real-time observation. All series have been obtained from the Archival Federal Reserve Data base at the St. Louis Fed.

\begin{tabular}{|c|c|c|c|}
\hline Mnemonic & Variable Description & TCode & Start Date \\
\hline AWHMAN & Average Weekly Hours of Production and Nonsupervisory Employees: Manufacturing & 2 & $11 / 1 / 1964$ \\
\hline AWHNONAG & Average Weekly Hours Of Production And Nonsupervisory Employees: Total private & 2 & $5 / 1 / 1970$ \\
\hline AWOTMAN & Average Weekly Overtime Hours of Production and Nonsupervisory Employees: Manufacturing & 2 & $8 / 1 / 1966$ \\
\hline CE16OV & Civilian Employment & 2 & $12 / 1 / 1964$ \\
\hline CLF16OV & Civilian Labor Force & 2 & $11 / 1 / 1964$ \\
\hline CPIAUCSL & Consumer Price Index for All Urban Consumers: All Items & 3 & $6 / 1 / 1972$ \\
\hline CURRDD & Currency Component of M1 Plus Demand Deposits & 3 & $11 / 1 / 1964$ \\
\hline CURRSL & Currency Component of M1 & 3 & $11 / 1 / 1964$ \\
\hline DEMDEPSL & Demand Deposits at Commercial Banks & 3 & $9 / 1 / 1964$ \\
\hline DMANEMP & All Employees: Durable goods & 2 & $11 / 1 / 1964$ \\
\hline DSPI & Disposable Personal Income & 2 & $1 / 1 / 1980$ \\
\hline DSPIC96 & Real Disposable Personal Income & 2 & $2 / 1 / 1980$ \\
\hline HOUST & Housing Starts: Total: New Privately Owned Housing Units Started & 2 & $12 / 1 / 1964$ \\
\hline HOUST1F & Privately Owned Housing Starts: 1-Unit Structures & 2 & $2 / 1 / 1972$ \\
\hline HOUST $2 \mathrm{~F}$ & Housing Starts: $2-4$ Units & 2 & $2 / 1 / 1973$ \\
\hline INDPRO & Industrial Production Index & 2 & $11 / 1 / 1964$ \\
\hline M1SL & M1 Money Stock & 3 & $12 / 1 / 1979$ \\
\hline M2SL & M2 Money Stock & 3 & $12 / 1 / 1979$ \\
\hline MANEMP & All Employees: Manufacturing & 2 & $11 / 1 / 1964$ \\
\hline NDMANEMP & All Employees: Nondurable goods & 2 & $11 / 1 / 1964$ \\
\hline OCDSL & Other Checkable Deposits & 3 & $2 / 1 / 1981$ \\
\hline PAYEMS & All Employees: Total nonfarm & 2 & $11 / 1 / 1964$ \\
\hline $\mathrm{PCE}$ & Personal Consumption Expenditures & 3 & $12 / 1 / 1979$ \\
\hline PCEC96 & Real Personal Consumption Expenditures & 2 & $3 / 1 / 1980$ \\
\hline PCEDG & Personal Consumption Expenditures: Durable Goods & 3 & $12 / 1 / 1979$ \\
\hline PCEDGC96 & Real Personal Consumption Expenditures: Durable Goods & 2 & $3 / 1 / 1980$ \\
\hline PCEND & Personal Consumption Expenditures: Nondurable Goods & 3 & $12 / 1 / 1979$ \\
\hline PCENDC96 & Real Personal Consumption Expenditures: Nondurable Goods & 2 & $3 / 1 / 1980$ \\
\hline PCES & Personal Consumption Expenditures: Services & 3 & $12 / 1 / 1979$ \\
\hline PCESC96 & Real Personal Consumption Expenditures: Services & 2 & $3 / 1 / 1980$ \\
\hline PFCGEF & Producer Price Index: Finished Consumer Goods Excluding Foods & 3 & $1 / 1 / 1982$ \\
\hline PI & Personal Income & 2 & $2 / 1 / 1966$ \\
\hline PPICFF & Producer Price Index: Crude Foodstuffs \& Feedstuffs & 3 & $1 / 1 / 1982$ \\
\hline PPICPE & Producer Price Index: Finished Goods: Capital Equipment & 3 & $1 / 1 / 1978$ \\
\hline PPICRM & Producer Price Index: Crude Materials for Further Processing & 3 & $3 / 1 / 1978$ \\
\hline PPIFCF & Producer Price Index: Finished Consumer Foods & 3 & $1 / 1 / 1982$ \\
\hline PPIFGS & Producer Price Index: Finished Goods & 3 & $1 / 1 / 1982$ \\
\hline PPIIFF & Producer Price Index: Intermediate Foods \& Feeds & 3 & $1 / 1 / 1982$ \\
\hline PPIITM & Producer Price Index: Intermediate Materials: Supplies \& Components & 3 & $3 / 1 / 1978$ \\
\hline SAVINGSL & Savings Deposits - Total & 3 & $12 / 1 / 1979$ \\
\hline SRVPRD & All Employees: Service-Providing Industries & 2 & $9 / 1 / 1971$ \\
\hline STDCBSL & Small Time Deposits at Commercial Banks & 3 & $12 / 1 / 1979$ \\
\hline STDSL & Small Time Deposits - Total & 3 & $12 / 1 / 1979$ \\
\hline STDTI & Small Time Deposits at Thrift Institutions & 3 & $12 / 1 / 1979$ \\
\hline SVGCBSL & Savings Deposits at Commercial Banks & 3 & $12 / 1 / 1979$ \\
\hline SVGTI & Savings Deposits at Thrift Institutions & 3 & $12 / 1 / 1979$ \\
\hline SVSTCBSL & Savings and Small Time Deposits at Commercial Banks & 3 & $12 / 1 / 1979$ \\
\hline SVSTSL & Savings and Small Time Deposits - Total & 3 & $12 / 1 / 1979$ \\
\hline TCDSL & Total Checkable Deposits & 3 & $3 / 1 / 1981$ \\
\hline UEMP15OV & Civilians Unemployed - 15 Weeks \& Over & 2 & $11 / 1 / 1964$ \\
\hline UEMP $15 \mathrm{~T} 26$ & Civilians Unemployed for $15-26$ Weeks & 2 & $1 / 1 / 1982$ \\
\hline UEMP27OV & Civilians Unemployed for 27 Weeks and Over & 2 & $1 / 1 / 1966$ \\
\hline UEMP5TO14 & Civilians Unemployed for 5-14 Weeks & 2 & $11 / 1 / 1964$ \\
\hline UEMPLT5 & Civilians Unemployed - Less Than 5 Weeks & 2 & $11 / 1 / 1964$ \\
\hline UEMPMEAN & Average (Mean) Duration of Unemployment & 2 & $1 / 1 / 1972$ \\
\hline UEMPMED & Median Duration of Unemployment & 2 & $1 / 1 / 1982$ \\
\hline UNEMPLOY & Unemployed & 2 & $12 / 1 / 1964$ \\
\hline UNRATE & Civilian Unemployment Rate & 1 & $2 / 1 / 1960$ \\
\hline USCONS & All Employees: Construction & 2 & $12 / 1 / 1964$ \\
\hline USFIRE & All Employees: Financial Activities & 2 & $12 / 1 / 1964$ \\
\hline USGOOD & All Employees: Goods-Producing Industries & 2 & $9 / 1 / 1971$ \\
\hline USGOVT & All Employees: Government & 2 & $12 / 1 / 1964$ \\
\hline USMINE & All Employees: Mining and logging & 2 & $12 / 1 / 1964$ \\
\hline USPRIV & All Employees: Total Private Industries & 2 & $8 / 1 / 1971$ \\
\hline USSERV & All Employees: Other Services & 2 & $12 / 1 / 1964$ \\
\hline USTPU & All Employees: Trade, Transportation \& Utilities & 2 & $12 / 1 / 1964$ \\
\hline USTRADE & All Employees: Retail Trade & 2 & $12 / 1 / 1964$ \\
\hline USWTRADE & All Employees: Wholesale Trade & 2 & $12 / 1 / 1964$ \\
\hline
\end{tabular}

